Review Paper

\title{
Microplastic-toxic chemical interaction: a review study on quantified levels, mechanism and implication
}

\author{
Andrew Wirnkor Verla ${ }^{1} \cdot$ Christian Ebere Enyoh ${ }^{1} \cdot$ Evelyn Ngozi Verla $^{2} \cdot$ Kieran Oharley Nwarnorh $^{3}$
}

(C) Springer Nature Switzerland AG 2019

\begin{abstract}
Current problem facing researchers globally is microplastics as well as toxic chemical pollution of the ecosystem. Microplastics carry toxic chemicals in the ecosystem serving as a vector for transport. In this study, a review of the literature has been conducted with the following objectives: (1) to summarize the concentrations of toxic chemicals such heavy metals and hydrophobic organic contaminants sorped on microplastics; (2) to evaluate their spatial distribution regarding adsorbed contaminant; (3) to discuss plausible mechanism by which microplastics adsorp or desorp toxic chemicals in the environment; (4) to discuss implications of their occurrence in air, water and soil media; and (5) to discuss the impact of ingested microplastics to human health. Microplastics are ubiquitous environmental contaminant. Concentrations of sorped toxic chemical varied by location which represents a local problem; industrialized areas (especially areas experiencing crude oil-related activities or have history of crude oil pollution) have higher concentrations than less industrialized areas. Ingestion of microplastics has been demonstrated in a range of marine and soil organisms as well as edible plants, thus possibly contaminating the base of the food web. Potential health effect to human is by particle localization, chemical toxicity and microbial toxins. We conclude by highlighting the gap in knowledge and suggesting key future areas of research for scientists and policymakers.
\end{abstract}

Keywords Air pollution $\cdot$ Micropollutants $\cdot$ Plastic debris $\cdot$ Risks $\cdot$ Soil pollution $\cdot$ Toxicity $\cdot$ Water pollution

\begin{tabular}{|c|c|c|c|}
\hline Abbreviations & & ICP-MS & Inductively coupled plasma mass \\
\hline PP & Polypropylene & & spectrophotometer \\
\hline PC & Polycarbonate & ICP-OES & Inductively coupled plasma-optical \\
\hline PS-E & Expanded polystyrene & & emission spectrometry \\
\hline PSU & Polyarylsulfone & FAAS & Flame atomic absorption spectrometry \\
\hline PS & Polystyrene & FP-XRF & Field-portable X-ray fluorescence \\
\hline TPE & Thermoplastic elastomers & cGC-ECD-MD & Capillary gas chromatograph equipped \\
\hline PET & Polyethylene terephthalate & & with electron capture detector and mass \\
\hline PMMA & Polymethyl methacrylate & & detector \\
\hline PVC & Polyvinyl chloride & GC-ECD & Gas chromatograph equipped with elec- \\
\hline PP & Polypropylene & & tron capture detector \\
\hline PA & Polyamides & LSC & Liquid scintillation counting \\
\hline PUR & Polyurethane & GC-ITMS & Gas chromatography-ion-trap mass \\
\hline AFS & Atomic fluorescence spectroscopy & & spectrometers \\
\hline
\end{tabular}

$\triangle$ Christian Ebere Enyoh, cenyoh@gmail.com; enyohchristian@yahoo.com | ${ }^{1}$ Group Research in Analytical Chemistry, Environment and Climate Change (GRACE\&CC), Department of Chemistry, Imo State University (IMSU), PMB 2000, Owerri, Imo State,

Nigeria. ${ }^{2}$ Department of Environmental Technology, Federal University of Technology, Owerri, Imo State, Nigeria. ${ }^{3}$ Department of Chemistry, Imo State University (IMSU), PMB 2000 Owerri, Imo State, Nigeria.

SN Applied Sciences (2019) 1:1400 | https://doi.org/10.1007/s42452-019-1352-0

Received: 17 July 2019 / Accepted: 24 September 2019 / Published online: 15 October 2019 


$\begin{array}{ll}\text { QqLIT-MS/MS } & \text { Liquid chromatography system coupled } \\ & \text { to a quadrupole linear ion-trap tandem } \\ & \text { mass spectrometer } \\ \text { PoTSs } & \text { Potentially toxic substances } \\ \text { BDE209 } & \text { Decabromo diphenyl ether } \\ \text { HCHs } & \text { Hexachlorocyclohexane isomers } \\ \text { PAHs } & \text { Polycyclic aromatic hydrocarbons } \\ \text { OCPs } & \text { Organochlorine pesticides } \\ \text { DDTs } & \text { Dichlorodiphenyltrichloroethane and } \\ & \text { related compounds } \\ \text { DDE } & \text { Dichlorodiphenyldichloroethylene } \\ \text { PBDEs } & \text { Polybrominated diphenyl ethers } \\ \text { PFCs } & \text { Perfluorinated compounds } \\ \text { PS-COOH } & \text { Polystyrene carboxylate } \\ \text { PFASs } & \text { Perfluoroalkyl substances } \\ \text { BPA } & \text { Bisphenol A } \\ \text { OPs } & \text { Octylphenols } \\ \text { NPs } & \text { Nonylphenols } \\ \text { BET } & \text { Brunauer-Emmett-Teller } \\ \text { PFO } & \text { Pseudo-first order } \\ \text { PSO } & \text { Pseudo-second order } \\ \text { PVDM } & \text { Pore-volume diffusion model } \\ \text { PVSDM } & \text { Pore-volume and surface diffusion } \\ & \text { model } \\ \text { FPMT } & \text { Film-pore mass transfer } \\ \text { SML } & \text { Surface microlayer } \\ \text { QS } & \text { Quorum sensing } \\ \text { SEM } & \text { Scanning electron microscopy } \\ \text { FTIR } & \text { Fourier transform infrared } \\ \text { SEM-EDS } & \text { Scanning electron microscopy with } \\ & \text { energy-dispersive X-ray spectroscopy } \\ \text { XRD } & \text { X-ray diffraction } \\ \text { IARC } & \text { International Agency for Research on } \\ & \text { Cancer } \\ \text { IMT } & \text { Internal mass transfer } \\ \text { EMT } & \text { External mass transfer } \\ \text { BCF } & \text { Bioaccumulation/concentration factors } \\ \text { ROS } & \text { Reactive oxygen species } \\ & \end{array}$

\section{Introduction}

Worldwide population continues to experience annual growth at an average rate of $1.68 \%$ between the years 1955 and 2015. World population was near 370 million, at the end of the Great Famine of 1315-1317 and the Black Death in 1350 [76]; now population have reached 7.7 billion people as of April 2019 revealing tremendous increase [182]. This tremendous increase has brought with it an increase in the amount of waste generated by people. Onthe-go lifestyles require easily disposable products, such as soda cans or bottles of water, but the accumulation of these products has led to increasing amounts of plastic pollution around the world (Fig. 1b).

Plastic is an organic polymer synthesized from fossil feedstocks such as natural gas, oil or coal. In modern times, the first plastic manufactured was in 1907 called "Bakelite". Due to the many benefits of plastics such as cheap, versatile, lightweight and resistant, its worldwide production which was only 0.35 million metric ton in 1950 has increased nearly 200 -fold, reaching 348 million metric tons in 2017 [172], with average annual growth of 9\% (Fig. 1a). In 2017 alone, about 34.8 million metric tons of plastics ended up in the marine environment (Fig. 1b). Overall, approximately $80 \%$ of the plastics polluting the marine environment come from land-based sources [12].

Plastics are comprised of two major category, viz. thermoplastics and thermosets. The former, thermoplastics are a family of plastics that are reversible and whose form can be easily altered by altering temperatures, e.g. polypropylene (PP), polycarbonate (PC), expanded polystyrene (PS$\mathrm{E})$, polyarylsulfone (PSU), polystyrene (PS), thermoplastic elastomers (TPE), polyethylene terephthalate (PET), polymethyl methacrylate (PMMA), polyvinyl chloride (PVC), polypropylene (PP), polyamides (PA) and fluoropolymer, etc., which are more common in the environment. However, thermosets are family of plastics that cannot be reversed when heated. They undergo a chemical change creating a three-dimensional network making them rigid, e.g. epoxy resins, vinyl ester, polyurethane (PUR), ureaformaldehyde, acrylic resin, silicone, melamine resin, phenolic resins, phenol-formaldehyde and unsaturated polyester, etc. Polluting plastics are biochemically inert due to their large molecule size and can potentially cause great harm to the environment. Additionally, they can persist long time in the environment and can be accumulated in open oceans, sedimentary habitats, soil and plant tissues $[39,40,64,65,203]$.

Large plastic (macroplastic) debris in the environment undergoes degradation by natural processes to form tiny plastic fragments called microplastics. Apart from the natural microplastic formation, it can also be formed by anthropogenic means. Their sources vary including cosmetics, clothing and industrial processes via urban wastewater treatment as well as nurdles, etc. [36]. In last 2 decade, the problem they create in the environment has caused a shift of attention by environmental analytical researchers from macroplastics pollution to microplastics. It is an emerging area of concern, and therefore, concern regarding plastic pollution has focused on sources, fate and ecological effects of microplastic particles in the environment $[22,39,40,62,136]$.

Microplastics can be defined as plastic materials of microsize dimension (often between the range of $1 \mu \mathrm{m}-5 \mathrm{~mm})[39,40]$. Their presence in the environment 


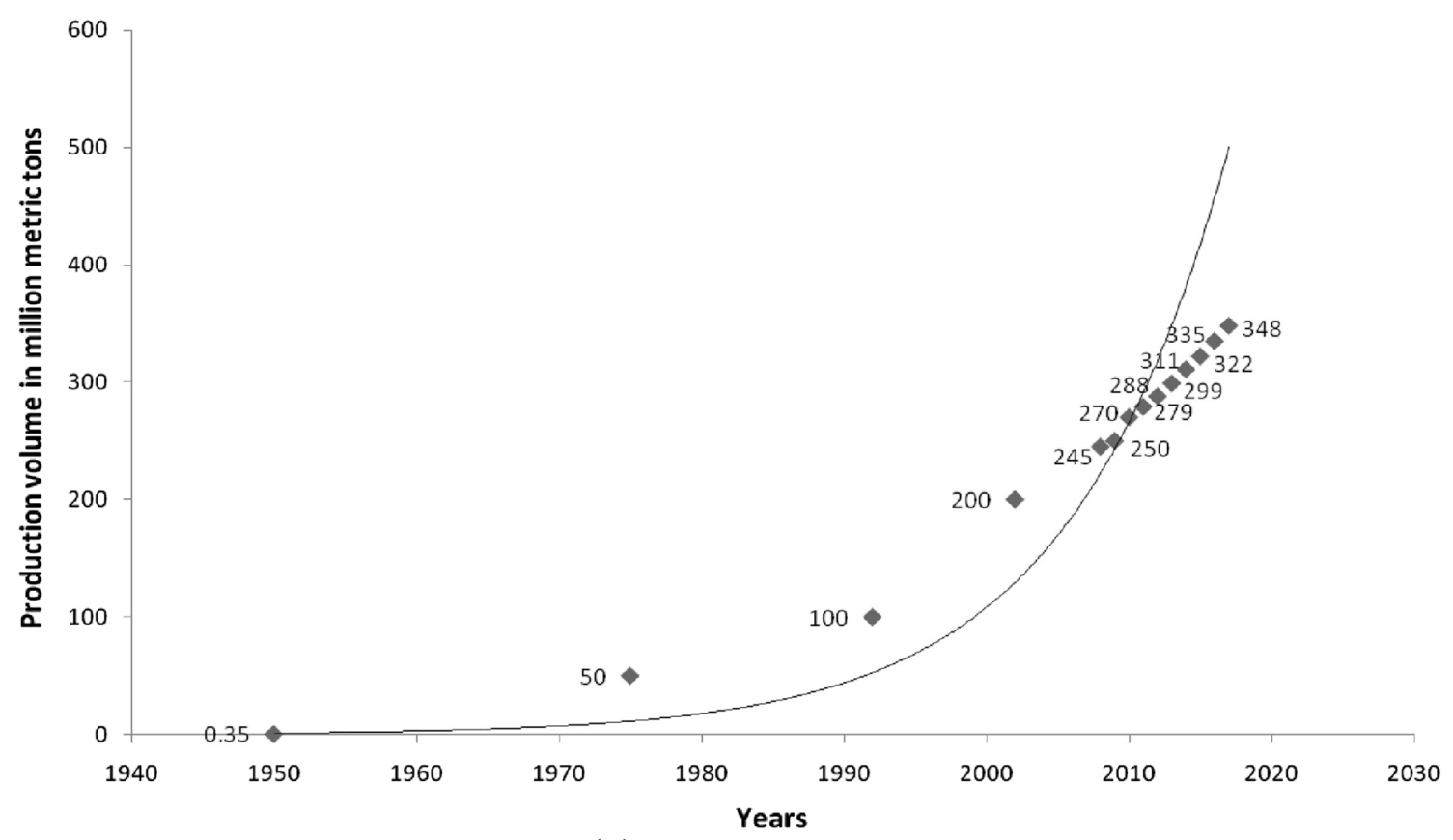

(a) World plastic production

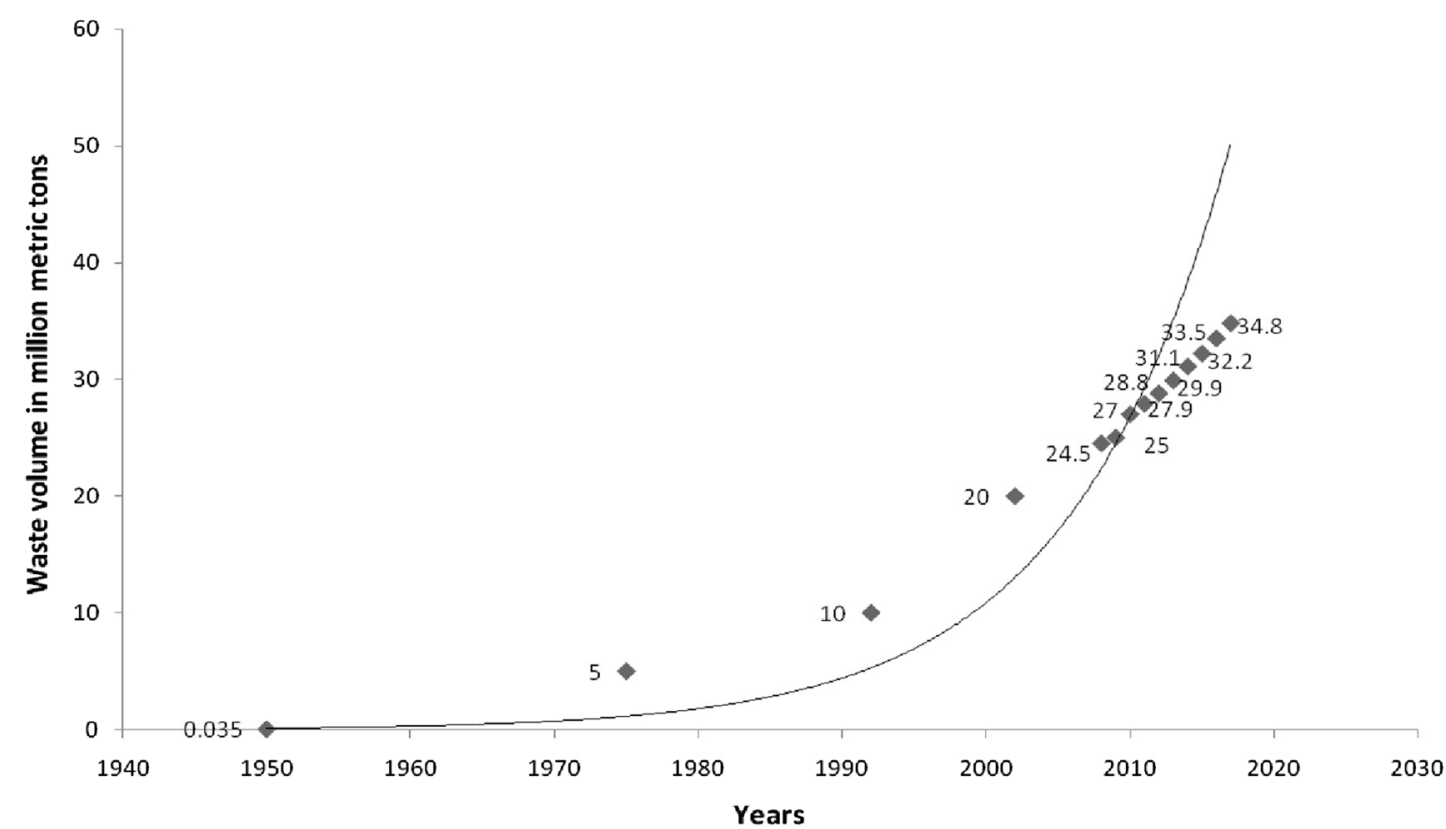

(b) World plastic waste generation

Fig. 1 World plastic production and generated waste from 1950 to 2017. (Data source: Statista [154]

is on continuous increase particularly in ocean as observed by the increase in the frequency and quantity of plastic ingested by seabirds $[7,23,24]$. Furthermore, they have recently been quantified in large quantity in soil ecosystem (reviewed by [203]) and in plant tissues [39, 40, 95]. Microplastics were included as a priority descriptor (10; Marine Litter) in the Marine Strategy Framework Directive
(MSFD) (Marine Litter) due to their impact in the marine environment [27].

One of the primary environmental risks associated with microplastics is that they are ubiquitous and bioavailable for injection by marine organisms $[26,184]$, soil organisms [78, 89, 92, 201, 202] and plant growing on microplastic polluted soils $[39,40]$. Studies have 
reported their presence in sea animals such as seabirds, fish, sandhoppers, sea turtle, crustacean and mussel $[12,21,45,118,162]$, soil invertebrates such as collembolan, oligochaeta (e.g. earthworms) and isopods [78, $89,92,201,202$ ] and in plants such as wheat plants [95]. In addition, their presence in table salts, potable water and human excreta has also been reported $[6,79,80]$. The health implication of their presence in animals is by blocking their digestive system and thus may lead to death of the animal or affect their feeding habit. However, in human, their health implication is yet to be ascertained, but plausible effects include lung inflammation as well as primary and secondary genotoxicity $[54,183]$.

Microplastics have been reported to be in tandem with other toxic chemicals serving a vector for their transports in the environment. These toxic chemicals by adsorption processes attach to microplastics in the environment and may get ingested through inhalation or contact. Then by desorption processes, they are released post-ingestion with potential for toxicity and/or accumulation in the food chain. Studies by $[16,17,58]$ reported organic pollutant (viz. polychlorinated biphenyls, PCBs) levels on marine plastic resin pellets, adsorbed either from plasticizers (commonly used before 1970s) or from ambient seawater. This behaviour of microplastics interacting with toxic chemicals can be problematic for the environment because adverse effects of these toxic chemicals have been associated with mutagenic, teratogenic and carcinogenic effects $[169,170]$. Examples of toxic chemicals that have been reported include heavy metals such as iron $(\mathrm{Fe})$, manganese $(\mathrm{Mn})$, aluminium (Al), lead $(\mathrm{Pb})$, copper $(\mathrm{Cu})$, silver $(\mathrm{Ag})$, zinc $(\mathrm{Zn})$ and hydrophobic organic contaminants (HOCs) also referred to as persistent organic pollutants (POPs) such as polyaromatic hydrocarbons (PAHs), organochlorine pesticides (OCPs) and polychlorinated biphenyls (PCBs). In this study, we presented a review of toxic chemicals (halogens, heavy metals and organic pollutants) concentrations on reported on microplastics found in the environment and animal, and provide their possible adsorption and desorption (release) mechanism and the implications of their interaction to man and his environment.

\section{Microplastics and toxic chemicals}

The surface area-to-volume ratio of microplastics is large, making them a good sorbent for toxic chemicals such as heavy metals and organic chemicals, i.e. POPs loading on its surface. Therefore, it acts as a conveyor of contaminants to organisms and between environment media. Generally, quantification of toxic chemicals from microplastic surface is mostly done using spectroscopic techniques following weak acid (e.g. $10 \% \mathrm{HNO}_{3}$ ) extraction for toxic metals while soxhlet-assisted $n$-hexane, methanol $(\mathrm{MeOH})$ or dichloromethane (DCM) extraction for organic pollutants. Concentrations are often reported in $\mu \mathrm{g} / \mathrm{g}$ or $\mathrm{mg} / \mathrm{kg}$ for heavy metals and halogens while $\mathrm{ng} / \mathrm{g}$ for organic pollutants. However, extraction chemical used is based on the type of microplastic. For example, methanol $(\mathrm{MeOH})$ was reported not to be efficient for PCBs, DDE and nonylphenol extraction from marine PP pellets [111], which maybe efficient for other microplastic types, viz. PE or PVC, etc. Some useful spectroscopic techniques for quantification of toxic chemicals after extraction have been reviewed in a recent study [172]. Summarily, the extractant and instrument for analysis, concentrations, types of toxic chemicals and study location reported in the literature on microplastic is presented in Table 1.

The concentrations varied among locations, indicating that the contamination represents a local problem; industrialized areas (especially areas experiencing crude oil-related activities or have history of crude oil pollution) have higher concentrations than remote areas. Also, concentrations are controlled by discolouration of microplastic with yellowed (discoloured) ones generally having higher concentration. However, few toxic metals and organic chemicals have generally been studied, which is very low when compared to over 300 plastic additives used with potential migration or release and potentially contaminate the environment. More study is needed to quantify more of these potentially toxic substances (PoTSs, coined by [61]) on microplastics. Majority of PoTSs are largely additives and have been reviewed recently by [61]. Also, research is needed to understand/know the sources of toxic chemicals found on microplastics, whether they came from additives or from ambient environment during particle exposure or they came from the two means working synergistically. Initial concentrations of a particular toxic chemical may be increased due to that particular chemical present in the plastic as additives. For example, very high concentration $(\sim 10000 \mathrm{ng} / \mathrm{g})$ of decabromo diphenyl ether (BDE209) on microplastics reported by [65] is most likely the result of its use as an additive rather than uptake from seawater. Another example is the concentrations of $\mathrm{Ni}$ and $\mathrm{Pb}$ in the microplastics from lake sediment and water which were about equal to those in the macroplastic litters [175], suggesting that the concentration was from additives used in the production of the plastic.

\subsection{Heavy metals}

Metals that are of high density are defined as heavy metals, specifically metals with density greater than $5 \mathrm{~g} / \mathrm{cm}^{3}$ 
and adversely affecting the ecosystem. Heavy metals are ubiquitous and find their way into the environment by natural means and through human activities [37, 172]. The sources of heavy metals in the environment are varied including natural weathering and mining of the earth's crust, soil erosion, urban runoff, industrial effluents, sewage discharge, pesticides application and many others $[115,75,172])$. Their pollution is particularly common where there are high anthropogenic pressures such as harbours and marinas. Similarly, harbours and marinas are also known to have high abundance of microplastics originated from human activities [12]. They interact while in the environment, with heavy metals attaching on the surface of microplastics.

Evidence of attachment of heavy metals onto microplastics has been highlighted in recent years, and reports have suggested that toxic metals are attached in high concentrations (Table 1). [67] studying adsorbed metals on polyethylene resin pellets collected from four beaches in South West England using inductively coupled plasma-mass spectrometer (ICP-MS) found mean concentrations range of metal distribution in the order: $\mathrm{Cr}$ $(44-430 \mu \mathrm{g} / \mathrm{g})>\mathrm{Ni}(40-131 \mu \mathrm{g} / \mathrm{g})>\mathrm{Fe}(41-97.8 \mu \mathrm{g} / \mathrm{g})>\mathrm{Co}$ $(17.7-107 \mu \mathrm{g} / \mathrm{g})>\mathrm{Cd}(1.09-76.7 \mu \mathrm{g} / \mathrm{g})>\mathrm{Al}$ $(16.9-55.8 \mu \mathrm{g} / \mathrm{g})>\mathrm{Zn} \quad(0.299-23.3 \mu \mathrm{g} / \mathrm{g})>\mathrm{Mn}$ $(1.16-20.5 \mu \mathrm{g} / \mathrm{g})>\mathrm{Cu}(0.064-1.32 \mu \mathrm{g} / \mathrm{g})$, respectively. These are high concentrations when in comparison with touchstone values for these metals in the marine environment.

Over a 12-month period, Rochman and co-workers (2014) studied metal accumulation on recently manufactured microplastics such as PET, HDPE, PVC, LDPE and PP, at three locations in San Diego Bay, USA, and reported final average concentrations for all polymers at the end of the 12 months were $4.16,3.8$ and $0.8 \mu \mathrm{g} / \mathrm{g}$ for $\mathrm{Zn}, \mathrm{Cd}$ and $\mathrm{Pb}$, respectively.

More recently, Munier and Bendell [117] via atomic absorption spectroscopy studied different toxic metals sorped on different microplastics formed from plastic debris (two types, recently manufactured and field) in nine urban intertidal regions in Burrard Inlet, Vancouver, British Columbia, Canada. The studied microplastics include PVC, nylon, PP, PET, PS, LDPE, HDPE, PC, PE and PUR while metals include $\mathrm{Cd}, \mathrm{Cu}, \mathrm{Zn}$ and $\mathrm{Pb}$. The range of mean metal concentration reported on the different microplastic surfaces was: Cd; $0.37 \mu \mathrm{g} / \mathrm{g}$ on PP to $1.77 \mu \mathrm{g} / \mathrm{g}$ on LDPE, Cu; $2.93 \mu \mathrm{g} / \mathrm{g}$ on nylon to $47.53 \mu \mathrm{g} / \mathrm{g}$ on LDPE, Zn; $4.3 \mu \mathrm{g} / \mathrm{g}$ on PVC to $604.24 \mu \mathrm{g} / \mathrm{g}$ on LDPE, Pb; $0.71 \mu \mathrm{g} / \mathrm{g}$ on PET to $17.68 \mu \mathrm{g} / \mathrm{g}$ on LDPE. LDPE generally had greater amounts of extracted metals. However, the greatest concentrations of $188 \mu \mathrm{g} / \mathrm{g}, 6667 \mu \mathrm{g} / \mathrm{g}, 698,000 \mu \mathrm{g} / \mathrm{g}$ and $930 \mu \mathrm{g} / \mathrm{g}$ of copper, zinc, lead and cadmium, respectively, were recovered from an unidentified object comprised of PVC. Data from the study suggest that the concentrations of recovered metal are similar from the two sources (recently manufactured and field) except for cadmium. These values were equally as great as that reported in previous studies [67, 137].

One study recently examined eight heavy metals in association with isolated microplastics from eight different farms in China [114]. Six of the farms were culture pond, and the remaining two farms were open areas for culturing sea cucumber. The analysis was done using inductively coupled plasma mass spectrophotometer (ICP-MS; for Cd), atomic fluorescence spectroscopy for arsenic (As) and other metals by inductively coupled plasma-optical emission spectrometry (ICP-OES). The reported range of the average concentrations of metals such as As, $\mathrm{Cd}$, $\mathrm{Cr}, \mathrm{Cu}, \mathrm{Mn}, \mathrm{Ni}, \mathrm{Pb}$ and $\mathrm{Zn}$ in association with microplastics was as follows: $0.35-2.89 \mathrm{mg} / \mathrm{kg}, 0.058-0.99 \mathrm{mg} / \mathrm{kg}$, $4.43-37.47 \mathrm{mg} / \mathrm{kg}, 1.37-21.67 \mathrm{mg} / \mathrm{kg}, 7.57-98.35 \mathrm{mg} / \mathrm{kg}$ ， $1.31-43.2 \mathrm{mg} / \mathrm{kg}, 2.56-40.8 \mathrm{mg} / \mathrm{kg}$ and $16.44-1190 \mathrm{mg} /$ $\mathrm{kg}$, respectively. Data from the study suggest that heavy metal concentration associated with the microplastics is not an indicator for the heavy metal concentrations in sea cucumber [114].

The reviewed studies have implicated high load on toxic metals on microplastics surface confirming the potentiality of microplastics as alternative source or sink of toxic metals contaminant in the marine environment. However, data are limited regarding toxic metals adsorption onto microplastics presence in soil or air as they are airborne $[1,29,38,54]$.

\subsection{Organic pollutant}

Organic pollutants are pollutants that are organic in nature, i.e. basically containing carbon covalently bonded with other compounds. Some are persistent when they are in the environment regarded as persistent organic pollutants (POPs) such as PCBs and OCPs. POPs are resistant to degradation through biochemical and photolytic processes [135] and can bioaccumulate with potential adverse impacts on the ecosystem. They are easily transported from their source and easily reconcentrated in the new environment to potential toxic levels. POPs sources could be from natural means such through volcanoes and various biosynthetic pathways or artificial means through total synthesis of chemicals [33]. POPs are lipophilic in nature and have low solubility. They tend to be associated with the suspended particles in the water column due to their low solubility and accumulate on microplastics. Therefore, in tandem with microplastics the negative effects could be doubled. There are many reports in recent years concerning loads of organic pollutant adsorbed onto microplastics. The literature reveals substances that have received 


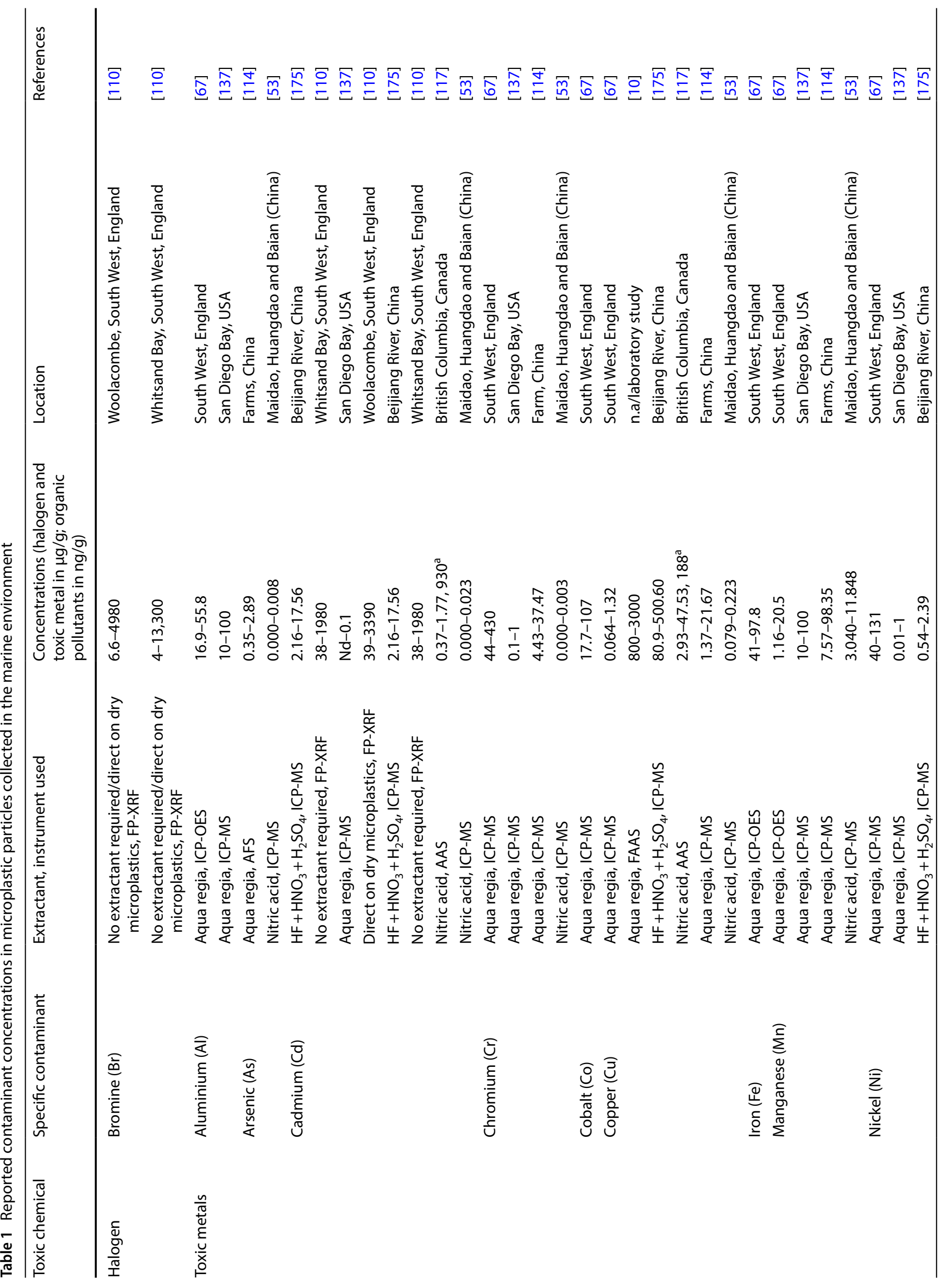




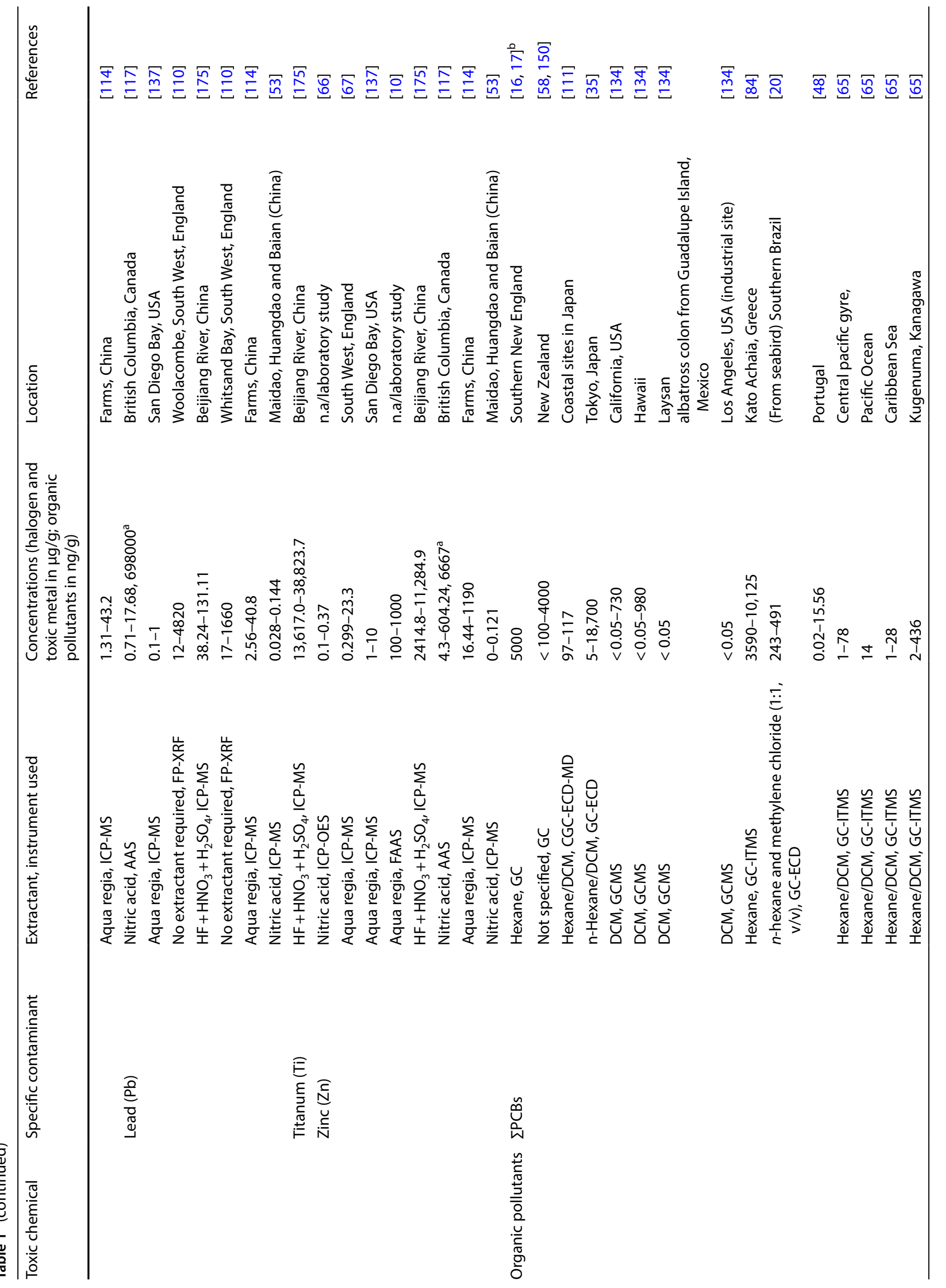




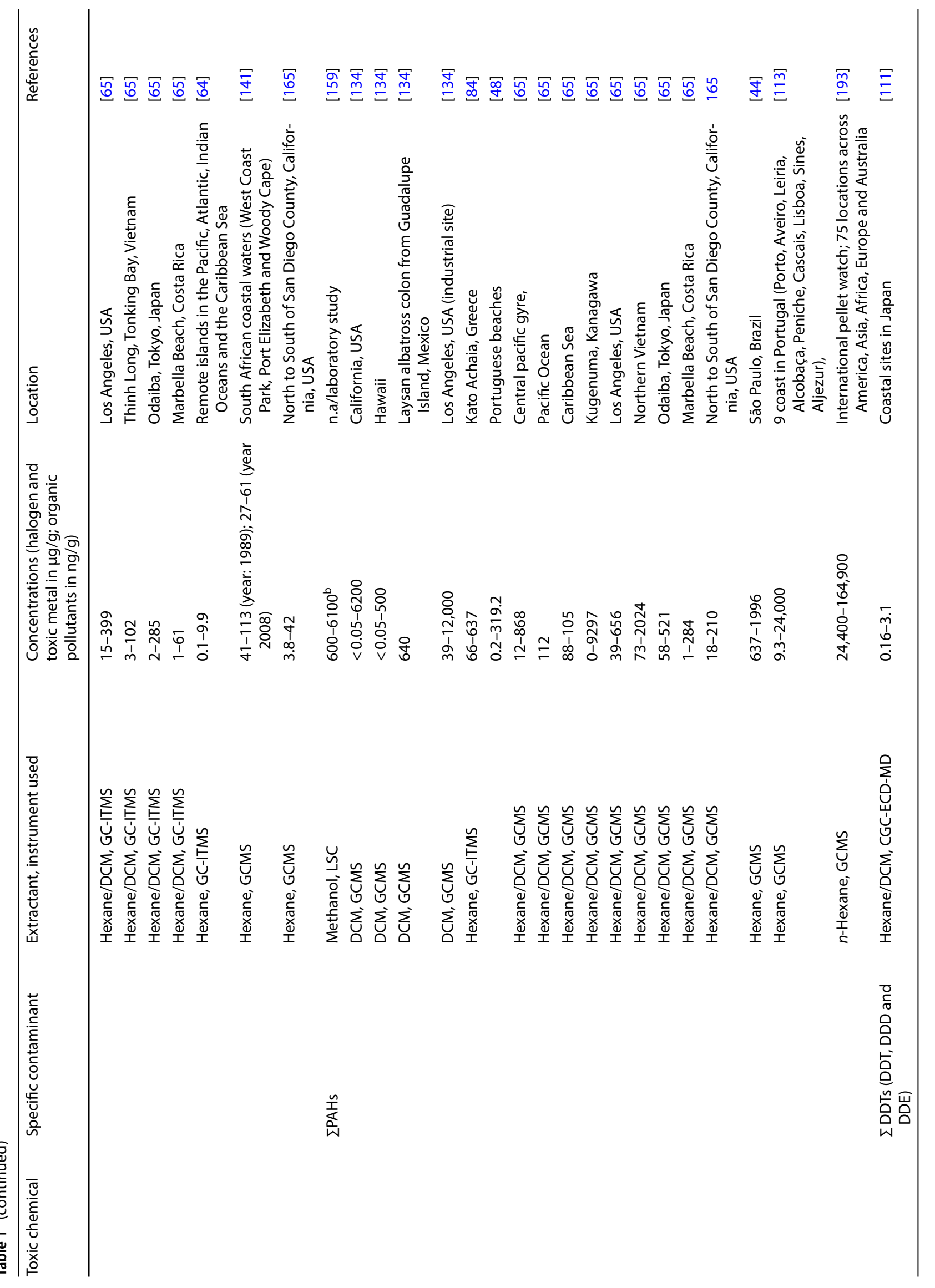




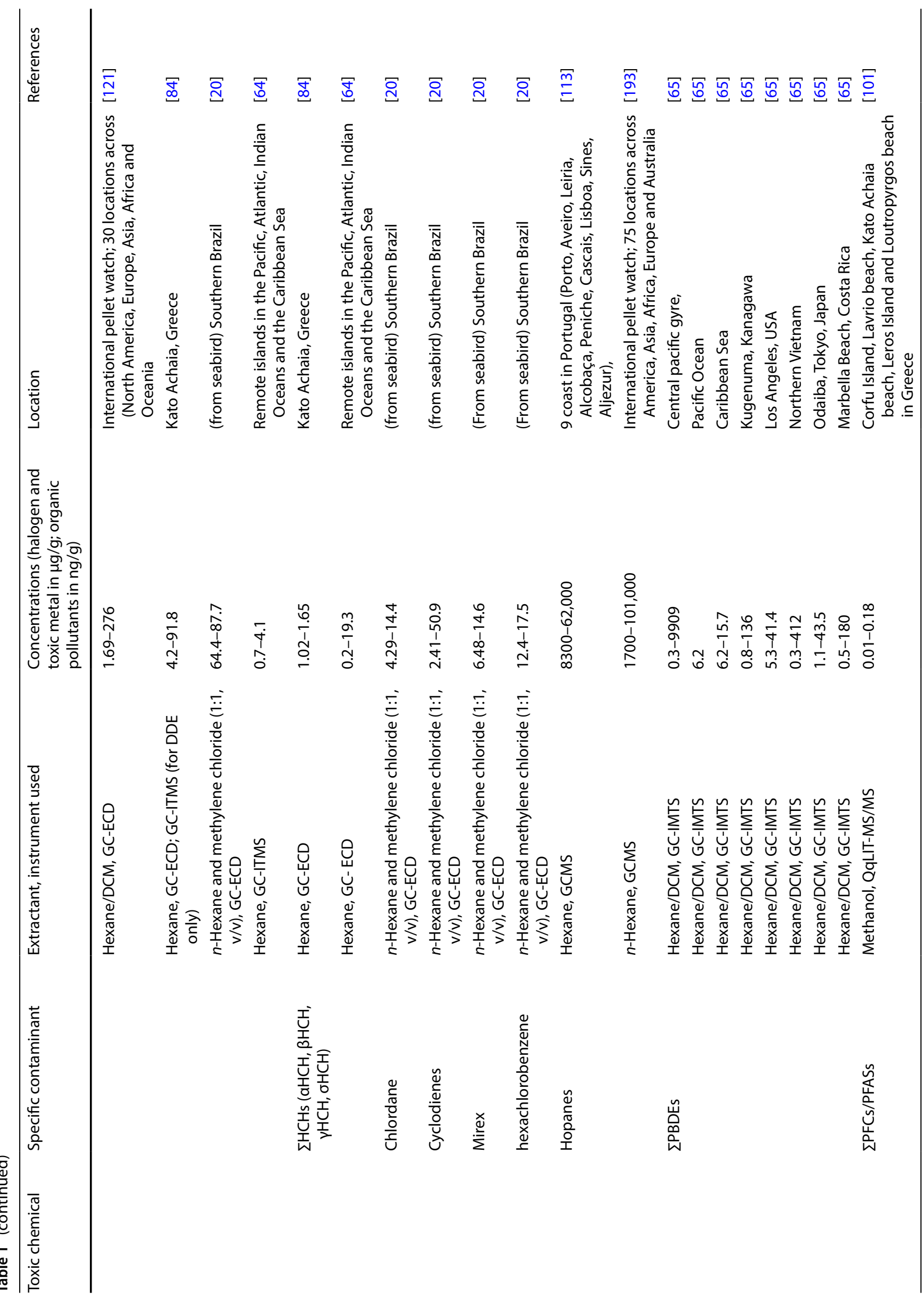




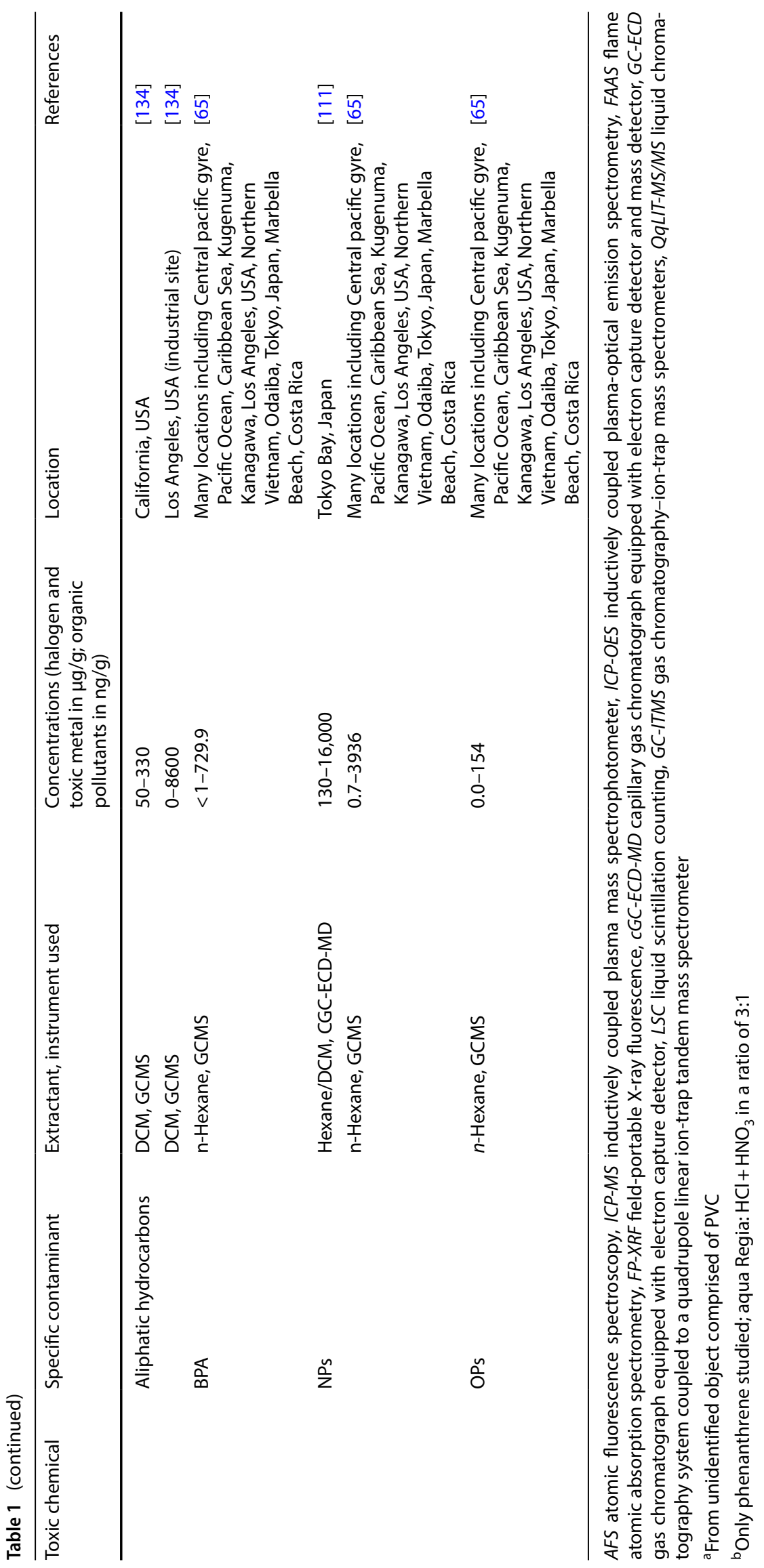

SN Applied Sciences 
much attention including polyaromatic hydrocarbons (e.g. fluoranthene, phenanthrene, etc.) and persistent organic pollutants such as polychlorinated biphenyls (PCBs), the insecticide DDT and its degradation product $p, p^{\prime}-D D E$, as well as hexachlorocyclohexane isomers ( $\mathrm{HCHs}$ ) (Table 1).

\subsubsection{Polychlorinated biphenyl's (PCB's)}

Polychlorinated biphenyl's (PCB's) are mixtures of up to 209 individual chlorinated compounds (known as congeners), of which 113 are known to be present in the environment [124]. The first report of PCB absorbed on PS in concentration of $5000 \mathrm{ng} / \mathrm{g}$, presumably from sea water, was reported in 1972 [17]. [58], when examining the accumulation and distribution of virgin plastic granules on New Zealand beaches, also reported the significant presence of PCBs sorbed to coloured polyethylene pellets found in sediment in high concentrations. Concentrations have increased over time to reaching $18,700 \mathrm{ng} / \mathrm{g}$ [74].

To the best of our knowledge, there was no literature concerning absorbed PCBs on microplastics from late 1970 s until early 2001 , thereby revealing a gap in data. However, since then 8 papers have been published since 2001 till date which covers many locations suggesting increasing interest following growing interest in microplastic pollution by researchers globally.

In 2001, Mato and colleagues analysed polypropylene resin pellets collected from four coastal sites in Japan: Kasai Seaside Park, Keihin Canal (Tokyo Bay), Kugenuma Beach (Pacific Ocean) and Shioda Beach (Sea of Japan) and identified PCBs in concentration range of 97-117 ng/g. Variability in PCBs concentrations in beached resin pellets from Tokyo, Japan, was also studied by [35]. Fifty-five resin pellets individually analysed revealed high variability in concentrations ranging from $<28$ to $2300 \mathrm{ng} / \mathrm{g}$, which is due to pellet discolouration and regional differences.

Rios et al. [134] analysed plastic samples collected from the North Pacific Ocean and coastal sites in California, Hawaii. Plastic samples were extracted with $150 \mathrm{ml}$ of dichloromethane for $12 \mathrm{~h}$ using Soxhlet apparatus, and the organic pollutant fraction analysed by GCMS. Total PCBs concentrations reported ranged from 27 to $980 \mathrm{ng} / \mathrm{g}$ while the congeners most common include PCB-52, 101, 118 and 170.

Karapanagioti et al. [84] analysed plastic pellets sampled from Kato Achaia, Greece. Sampled pellets were extracted with hexane and PCBs concentration measured by gas chromatograph equipped with ion-trap mass spectrometer on MS/MS mode. Results revealed PCBs concentration ranging from $3590 \mathrm{n} / \mathrm{g}$ to $10,125 \mathrm{ng} / \mathrm{g}$. Furthermore, $\mathrm{PCB}-138$ was reported as the most common in comparison with other PCBs congeners [84].
Frias et al. [48] reported PCBs concentration ranged from 0.02 to $15.56 \mathrm{ng} / \mathrm{g}$ on microplastics found on two beaches in Portugal. Hirai et al. [65] reported PCBs concentration range of $1-1000 \mathrm{ng} / \mathrm{g}$ from microplastic fragments sampled from open oceans, remote and urban beaches. Plastic resin pellets collected from remote islands in the Pacific, Atlantic and Indian Oceans and the Caribbean Sea were analysed for PCBs by Heskett et al. [64], and their report revealed total PCBs concentrations range of $0.1-9.9 \mathrm{ng} / \mathrm{g}$.

Long-term decrease (1989-2008) in total PCBs concentrations on yellow polyethylene pellets from three South African coastal waters (West Coast Park, Port Elizabeth and Woody (ape) was reported by Ryan et al. [141]. The concentrations dropped was from $113 \mathrm{ng} / \mathrm{g}$ (1989) to $61 \mathrm{ng} / \mathrm{g}$ (2008) in West Coast Park; 41 ng/g (1989) to $27 \mathrm{ng} / \mathrm{g}$ (2008) in Port Elizabeth; and $56 \mathrm{ng} / \mathrm{g}$ (1989) to $25 \mathrm{ng} / \mathrm{g}$ (2008) in Woody Cape, respectively. The reduction may be a function of plastic age $[111,134]$. With the view of establishing background concentrations for International Pellet Watch, Heskett and co-workers in 2012 measured POPs in plastic resin pellets from remote islands in Spain (Canary Islands), British territory (Saint Helena), Australia (Territory of the Cocos (Keeling) Islands), USA (Island of Hawaii and Island of Oahu) and Barbados (Island of Oahu) and revealed median concentrations of total-13 PCBs in pellet samples from the remote islands ranged from 0.1 to $9.9 \mathrm{ng} / \mathrm{g}-\mathrm{pel}$ let. Concentration was 1-3 order less than those in pellets from industrialized coastal zones as reported by [121], suggesting that plastic pellets from industrialized zone
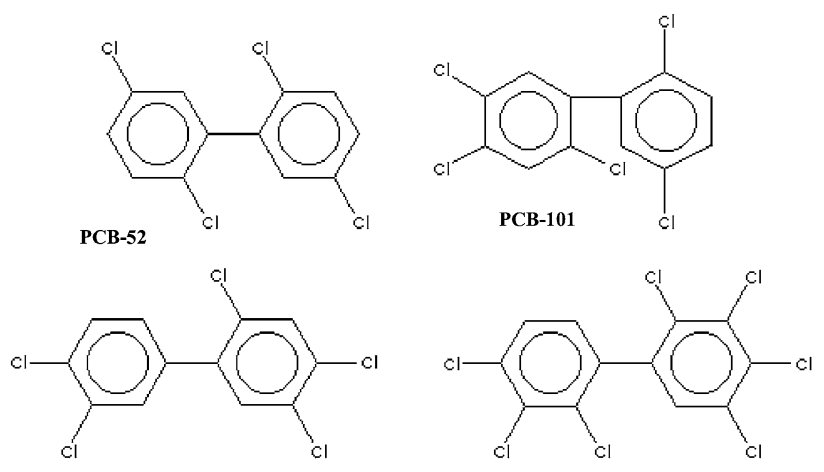

PCB-118

PCB-170

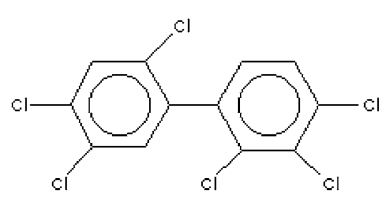

PCB-138

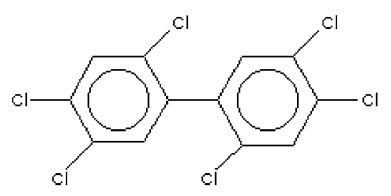

PCB-153

Fig. 2 Chemical structures of common PCB congeners found on microplastic surface from beaches 
accumulate higher concentration of PCBs. The chemical structures of common congeners of PCBs reported in the literature are presented in Fig. 2.

\subsubsection{Polyaromatic hydrocarbon (PAHs)}

Polycyclic aromatic hydrocarbons (PAHs) sometimes called polynuclear aromatic hydrocarbons are composed of multiple aromatic rings (organic rings in which the electrons are delocalized) with simplest form of two rings (naphthalene) and three rings (anthracene and/or phenanthrene). Studies have reported their presence on microplastics at varying concentrations of which fluoranthene (Fluo), phenanthrene (Phe), anthracene (Anth), 3-methylphenanthrene (3-MP), 9-methylphenanthrene (9-MP), 2-methylphenanthrene (2-MP), 1-methylphenanthrene (1-MP), pyrene (Py), benzo[b]fluorene (a-MPy), 2-methylpyrene (c-MPy), 1-methylpyrene (d-MPy), benzo[b]fluoranthene (BbF), chrysene (Chry), 5 methylated isomers of chrysene or benz[a]anthracene, 4-methylpyrene (b-MPy), benzo[j] fluoranthene $(\mathrm{BjF})$, benz[a]anthracene $(\mathrm{BaA})$, benzo[k] fluoranthene (BkF), benzo[e]pyrene (BeP), benzo[a]pyrene (BaP), perylene (Pery), indeno[1,2,3-cd]pyrene (IndPy), benzo[ghi]perylene (BghiP), 4H-cyclopenta[def]phenanthrene (CPP) and coronene (Cor) have generally been quantified [134, 142, 193, 84].

A study conducted by Rios et al. [134] on microplastics sampled from North Pacific Gyre, and selected sites in California, Hawaii, and from Guadalupe Island, Mexico, reported adsorbed PAHs concentrations in the range of 39-1200 ng/g. In the same study, analysis of discoloured (yellowed) plastic revealed higher concentration range of $6100-12,000 \mathrm{ng} / \mathrm{g}$ [134]. The fragment samples taken from the bank of the San Gabriel River, at the beach, and on the sea surface also presented high concentrations (6200-9200 $\mathrm{ng} / \mathrm{g}$ ) of PAHs [134]. The literature data pointed out that discoloured microplastics accumulate higher concentration of PAHs than newer microplastics.

Teuten et al. [159] observed PAH (phenanthrene) at concentrations $10^{6}$ higher on polystyrene pellets than in surrounding water. Concentration of total PAHs in pellets (ng/g-pellet) sampled from Kato Achaia, Greece, ranged from 66 to $637 \mathrm{ng} / \mathrm{g}$ [84]. However, lower PAH concentration ranging from 0.2 to $319.2 \mathrm{ng} / \mathrm{g}$ was reported from microplastics found on two Portuguese beaches [48]. Also, [65] analysed plastic fragments $(<10 \mathrm{~mm})$ collected from pelagic and neritic stations and revealed a range of $1-10,000 \mathrm{ng} / \mathrm{g}$ for PAHs. The variability in the concentration and composition of PAHs at different sediment depths in a sandy beach located in Santos Bay on the south-eastern coast of São Paulo state, Brazil, was studied [44]. In the study, some variability with depth with highest concentration of PAHs in pellets collected in the surface layer of the sediment $(0-10 \mathrm{~cm}$ with $1996 \mathrm{ng} / \mathrm{g})$, with smaller peaks recorded at $60-70 \mathrm{~cm}$ and $30-40 \mathrm{~cm}(1336 \mathrm{ng} / \mathrm{g}$ and $1004 \mathrm{ng} / \mathrm{g}$, respectively). The concentration of total priority PAHs ranged between 198 and $1042 \mathrm{ng} / \mathrm{g}$ while total PAHs ranged from 637 to $1996 \mathrm{ng} / \mathrm{g}$. Generally, in comparison with potential toxicity level set by NOAA showed that the reported concentrations were low [44].

Mizukawa et al. [113] reported PAH concentration variations of up to 2 orders of magnitude between individual countries within a region. More recently, [193] following IPW monitoring study reported that Europe at Sao Torpes Beach, Sines in Portugal (24,400 ng/g-pellet) and Forth Estuary in UK (164,900 ng/g-pellet) were highest in concentrations of total PAHs on plastic pellets collected from 75 locations in 26 countries. The authors attributed these high concentrations to crude oil pollution. Generally, based on the categorization for International Pellet Watch, the recorded PAHs levels were moderate to extreme for Western Europe (especially around the North Sea) while moderate to high concentrations were reported for East Asia (Japan and China) and North America, respectively. However, Southeast Asia, Oceania, South America and Africa (except for site with history of oil spillage or experiences petroleum-related activities) recorded low concentrations. For example, plastic pellets collected from Chemu Lagoon Beach located close to Tema oil refinery in Ghana was highly polluted with $2751 \mathrm{ng} / \mathrm{g}$-pellet [193], thus confirming the influence of crude oil pollution in increasing levels of PAHs loaded on the surface of microplastics.

\subsubsection{Organochlorine Pesticides (OCPs)}

Organochlorine $(\mathrm{OC})$ pesticides are synthetic pesticides which belong to the group of chlorinated hydrocarbon derivatives widely used in chemical industry and in agriculture. Reported OCPs in the literature include dichlorodiphenyltrichloroethane and related compounds (DDTs), hexachlorocyclohexane $(\mathrm{HCH})$ isomers, chlordanes, cyclodienes, mirex, hopanes: natural substances, hexachlorobenzene (Table 1).

2.2.3.1 Dichlorodiphenyltrichloroethane and related compounds (DDTs) Dichlorodiphenyldichloroethylene (DDE) concentrations on microplastics (specifically, PP) collected from four coastal sites in Japan were reported to range from 0.16 to $3.1 \mathrm{ng} / \mathrm{g}$ [111]. Ogata et al. [121] reported the occurrence of DDTs (DDT, DDD and DDE) in plastic pellets collected at 30 beaches from 17 countries and 5 continents (North America, Europe, Asia, Africa and Oceania). The highest concentrations of total DDTs from the International Pellets Watch (IPW) implicated Hermosa Beach, California, USA (267 ng/g), while Bay of Maputo, Mozambique and South Durban, South 
Africa had concentrations of $4.49 \mathrm{ng} / \mathrm{g}$ and $2.43 \mathrm{ng} / \mathrm{g}$, respectively [121]. Dichloro-diphenyl-trichloroethane (DDT) and dichlorodiphenyldichloroethane (DDD) concentrations were measured by GC equipped with electron capture detector (GC-ECD) while DDE concentrations were measured by gas chromatograph equipped with ion-trap mass spectrometer on MS/MS mode from plastic pellets sampled from Kato Achaia beach, Greece [84]. The reported concentrations ranged from $0.8 \mathrm{ng} / \mathrm{g}$ to $1.9 \mathrm{ng} / \mathrm{g}$ for DDT, $0.2 \mathrm{ng} / \mathrm{g}$ to $2.6 \mathrm{ng} / \mathrm{g}$ for DDD and $2.7 \mathrm{ng} / \mathrm{g}$ to $88 \mathrm{ng} / \mathrm{g}$ for $\mathrm{DDE}$, respectively. A study by Colabuono et al. [20] on OCPs on microplastics ingested by seabird revealed total DDT concentration range of 64.4-87.7 ng/g. Also, among the 25 different and related OCPs studied, p,p-DDE had the highest concentrations ranging from 68.0 to $99.0 \mathrm{ng} / \mathrm{g}$. The concentrations of DDT and related compounds generally vary by location and methodology. Another conclusion is that concentrations found on microplastics ingested by seabirds were higher than in sediment. In 2012, DDTs concentrations (sum of $p, p-D D T, p, p-D D D$ and $p, p-D D E$ ) were reported to ranged from 0.7 to $4.1 \mathrm{ng} / \mathrm{g}$-pellet from plastic pellets sampled from remote islands in six locations [64]. The study further implicated DDT (70-91\% of total) as the most distributed over the degradation products, viz. DDD and DDE.

2.2.3.2 Hexachlorocyclohexane $(\mathrm{HCH})$ isomers Hexachlorocyclohexanes $(\mathrm{HCHs})$ concentrations measured by $\mathrm{GC}$ equipped with electron capture detector (GC-ECD) from plastic pellets sampled from Kato Achaia beach, Greece, revealed total $\mathrm{HCH}$ in the range of $1.02-1.65 \mathrm{ng} / \mathrm{g}$ [84]. Also in the study, the different $\mathrm{HCH}$ isomers studied showed concentrations ranging from 0.2 to $0.31 \mathrm{ng} / \mathrm{g}$ for $\mathrm{aHCH}$, from 0.48 to $0.53 \mathrm{ng} / \mathrm{g}$ for $\beta \mathrm{HCH}$, from 0.15 to $0.32 \mathrm{ng} / \mathrm{g}$ for $\mathrm{yHCH}$ and from 0.06 to $0.25 \mathrm{ng} / \mathrm{g}$ for $\sigma \mathrm{HCH}$ [84]. These concentrations were generally low and close to procedural blank used in the study, suggesting low $\mathrm{HCH}$ in Kato Achaia beach, Greece. A study reported in 2012 on plastic pellets collected from remote islands around Europe and America pelagic zones found $\mathrm{HCH}$ concentrations in the range of $0.2-19.3 \mathrm{ng} / \mathrm{g}$-pellet [64]. $\mathrm{HCH}$ isomers had concentration range of $0.0-0.7 \mathrm{ng} / \mathrm{g}(\mathrm{aHCH})$, nd- 0.7 $(\beta \mathrm{HCH}), \mathrm{nd}-15.8(\mathrm{\gamma HCH})$ and $\mathrm{nd}-1.6(\sigma \mathrm{HCH})$, respectively. Although the concentrations were low generally, larger concentrations were recorded at St. Helena Island attributed to lindane use on island during the study period [64], thus suggesting that concentrations are influenced by local activities.

2.2.3.3 Chlordane, cyclodienes, mirex, hexachlorobenzene and hopanes Reported levels of chlordane, cyclodienes, mirex and hexachlorobenzene adhered to microplastics in the natural environment are lacking due to lack of data. However, there are reports of their adsorption on microplastics collected from seabird. Colabuono et al. [20], using gas chromatograph with an electron capture detector (GC-ECD), assessed microplastics found in the digestive tract of eight species of Procellariiformes collected in southern Brazil and reported total chlordane levels ranging from 4.29 to $14.4 \mathrm{ng} / \mathrm{g}$, total cyclodienes levels ranged from 2.41 to $50.9 \mathrm{ng} / \mathrm{g}$, total mirex levels ranged from 6.48 to $14.6 \mathrm{ng} / \mathrm{g}$ and total hexachlorobenzene ranged from 12.4 to $17.5 \mathrm{ng} / \mathrm{g}$, respectively. The authors pointed that the levels were similar to levels in the tissues of majority of seabirds around the world. The authors recommended that studies on the contamination of these pollutants in seabirds with high frequencies of plastic ingestion and the development of research that links such information are essential to understanding whether (and how) the transfer of organic pollutants from plastics to marine organisms should be conducted [20].

High concentrations of total hopanes (8300$62,000 \mathrm{ng} / \mathrm{g}$ ) were recorded in a monitoring study on microplastics sampled from eight locations on the coast of Portugal [113]. Data from the study revealed that, among the congeners, homohopanes (ranging from $C_{31}$ to $C_{35}$ ) were relatively abundant. More recently, following IPW from Western Europe, East Asia, Oceania, South America and Africa, [193] reported total hopanes level in plastic resin pellet ranged from 1700 to $101,000 \mathrm{ng} / \mathrm{g}$ which showed no spatial pattern. However, hopanes concentrations sorped on microplastics are influenced by crude oilrelated pollution. Reports have indicated higher concentrations of hopanes in the Northern Hemisphere (China, Japan, UK, France, Germany, Portugal and Spain), particularly around the North Sea due to these regions having a long history of oil development and oil tanker routes [193]. Zakaria et al. [194, 195] pointed that crude oil origin affects the composition of hopanes and can be used for source identification of oil pollution.

\subsubsection{Other organic pollutants}

2.2.4.1 Polybrominated diphenyl ethers (PBDEs) PBDEs rarely degrade when in the environment but under certain conditions, some PBDEs compounds (e.g., decaBDE) may degrade by direct photolysis to form lower-brominated congeners. Although their carcinogenic effect is not yet established, EPA assigns the cancer category group D (not classifiable as to human carcinogenicity) to mono-, di-, tri-, tetra-, penta-, hexa-, octa- and nonaBDEs and no classification for specific congeners 2, $2^{\prime}, 4,4^{\prime}$-tetraBDE, $2,2^{\prime}, 4,4^{\prime}, 5^{\prime}$-pentaBDE and $2,2^{\prime}, 4,4^{\prime}, 5,5^{\prime}$-hexaBDE due to inadequate information on their cancer risk [11]. Just like many other hydrophobic contaminants, PBDEs have been 
reported to adhere on plastic fragment from marine environment. The distribution of PBDEs levels on microplastics is spatially based (or regional differences), plastic type and dependent on local anthropogenic activities. For example, in terms of microplastic type, very high concentration (9909 $\mathrm{ng} / \mathrm{g}$ ) was reported on PP collected from central pacific gyre while from the same study area, total PDBEs level on PE was very low (0.3 ng/g) [65]. Generally in the study, the levels ranged from 0.3 to $9909 \mathrm{ng} / \mathrm{g}$ with remote areas having lower concentration compared to open seas where people frequent and under high anthropogenic pressure. PBDEs are airborne pollutant and can be transported from the continents to both coastal and open sea through aerosol [52] and dust. Microplastics are airborne pollutant $[1,29,54]$, and they may transport PBDEs with them. Therefore, studies are required to quantify PBDEs levels on atmospheric microplastics in many locations of the world to inform on ecological as well as human risk associated with PBDEs adhered on airborne microplastics.

BDE-209 is one common PBDEs congener normally occurring in very high concentrations, although also depended on quantity of BDE-209 additives, anthropogenic activities and vary by location. Hirai et al. [65] reported $100 \%$ of total PBDE was BDE-209 in an open ocean while a $1 \%$ for location in remote area. Generally, the level of total PDBEs correlated strongly with BDE-209 level; high BDE-209 concentrations will cause high total PDBE concentrations on microplastic.

2.2.4.2 Perfluorinated compounds (PFCs) PFCs also called perfluorinated alkyl substances (PFASs) are a large group of chemicals used in industrial and commercial applications due to their inertia and resistance to physical, chemical and biological degradation [102]. They have been related to different toxicological effects (e.g. disruption of the thyroid hormones and the metabolism of high-density lipoproteins, cholesterol and triglycerides $[90,126]$. Data on adsorbed PFCs concentrations on microplastics are limited. However, one study determined levels and fate of perfluoroalkyl substances in beached plastic pellets collected from Corfu Island, Lavrio beach, Kato Achaia beach, Leros Island and Loutropyrgos beach in Greece and reported concentration range of $10-180 \mathrm{ng} / \mathrm{Kg}$ [101]. A further study by Llorca and co-workers on the capacity of three microplastics, which include HDPE, PS and polystyrene carboxylate (PS-COOH), to sorb 18 perfluoroalkyl substances (PFASs, including carboxylic acids, sulphonates and one sulphonamide) from the surrounding waters (freshwater and seawater) revealed the order of PS $>$ PS- $\mathrm{COOH}>\mathrm{HDPE}$ for their adsorption of PFASs [103]. There is need for more study to quantify concentrations of adsorbed PFASs on microplastics from more locations, in order to understand better their distribution in the environment.
2.2.4.3 Bisphenol A (BPA) BPA is a constituent monomer in polycarbonate which is widely used in food and beverage containers. The compound is persistent, but their instability within plastic products facilitates leaching and their high prevalence in aquatic environments has been widely reported, particularly in landfill leachates [174]. Studies are lacking regarding the level of bisphenol A adhered on microplastic surface. One study reported concentrations range of $<1-729.9 \mathrm{ng} / \mathrm{g}$ for microplastic sampled from remote, open ocean and urban beaches from America and Europe [65].

2.2.4.4 Aliphatic hydrocarbons Aliphatic hydrocarbons have not been reported to negatively affect organisms in the environment, perhaps due to their easy degradation when compared to other toxic pollutants such as PAHs, PCBs and OCPs [179]. However, those of higher carbon groups $\left(\mathrm{C}_{28}-\mathrm{C}_{40}\right)$, particularly some n-alkanes, are difficult to be degraded biologically $[9,123]$. Aside this, Rios et al. [134] stated that they can help in differentiating organic matter sources in the environment whether biogenic or petrogenic. Evidence of their concentrations on microplastics is very limited. One study reported a total aliphatic concentration $\left(C_{12}-C_{36}\right)$ range of $1.1-8600 \mathrm{ng} / \mathrm{g}$ from sampled plastic pellets from the North Pacific Ocean, and coastal sites in California, Hawaii and regurgitated stomach contents from a Laysan albatross colony on Guadalupe Island, Mexico. Also from the study, the industrial sites had highest levels of $n$-alkanes compared to other study locations. This finding suggests that industrial activities may increase levels of aliphatic hydrocarbons adhered onto microplastics.

2.2.4.5 Octylphenols (OPs) and Nonylphenols (NPs) Derivatives of OPs and NPs are used as additives for plastics and some other products like laundry and dish soap, detergent, paint, etc. Many products that contain OPs and NPs have "down-the-drain" applications. Therefore, they are easily introduced into the water supply, river water, sediments, soil and groundwater [160]. Another source of their presence in the environment involves the breakdown of ethoxylates (octylphenol ethoxylates; OPEs, and noylphenol ethoxylates; NPEs) as well as leaching from plastic debris [153]. OPs and NPs persist in the environment and are particularly toxic with their endocrine disrupting activities $[50,106,148]$.

Evidence of their presence on microplastics is limited especially for OPs. Information concerning the concentrations of OPs on microplastics was only reported in a study by Hirai et al. [65]. OPs presence has been reported in leachates $(0.1-154 \mathrm{ng} / \mathrm{g})$ from waste disposal sites (containing considerable amounts of plastics) across Asia (reviewed by [158]. The review studies did not attempt 
to confirm their sources whether it is from degrading plastics present at the waste disposal site, which may be achieved using the principal components analysis. On the other hand, the concentration of nonylphenols was studied on plastic pellets collected in 1997 and 1998 from four beaches in Tokyo Bay [111]. In their report, the levels ranged from 130 to $16,000 \mathrm{ng} / \mathrm{g}$, concentration that was 2 orders higher than sediment from the same location. The concentrations of NPs in the environment have been reported to be reducing over the years. Studies reported in 2007 and 2011 found lower concentrations of NPs, concentrations which ranged from 0.7 to $3936 \mathrm{ng} / \mathrm{g}[65,159]$. We found no recent study published on OPs and NPs levels adhered on microplastics. This exposes the scarcity of data concerning their distribution in the environment by microplastics. This can be a call for concern as consumption of these chemicals can be hazardous for both terrestrial and aquatic animals.

\section{Adsorption and desorption mechanism of toxic chemicals onto microplastics}

Microplastics serve as carrier for toxic chemicals such as heavy metals and organic pollutants in the environment. This is possible by pollutants adsorbing onto microplastics surface. The adsorption of toxic chemicals on microplastics surface is due to the large surface area of microplastics (as high as $4.37 \mathrm{~m}^{2} / \mathrm{g}$; measured using the Brunauer-Emmett-Teller (BET) method reported by Teuten et al. [159]. Furthermore, induced electrostatic charge on the highly resistive plastic caused by high-speed manufacturing equipment during plastic production can increase the pickup of pollutants while in the environment. Some studies in 1950s have demonstrated the effect of static charge on plastic surface to pickup of atmospheric dust $[146,181]$. Electrostatic charge as high as $-9 \mathrm{kv}$ was measured on moving plastic, which make them more susceptible to contamination by airborne pollutants [88]. Data from the study by [93] showed that pollutant can adhere to the plastic surface under many environmental conditions.

The adsorption and desorption mechanisms of toxic chemicals to plastics are varied and complex and remain relatively unexplored by researchers. The lack of exploration, hence lack of the information, is partly due to lack standard analytical procedure or operation protocols (SOP) [172]. However, the plausible mechanism of sorption and desorption of toxic chemicals onto or from microplastics surface is discussed in this section.

The sorption/desorption mechanism can be monitored or studied using some spectroscopic techniques (reviewed by Verla et al. [172]) as well as using different sorption kinetics and isotherms models such as pseudo-first-order
(PFO), pseudo-second-order (PSO), or the intra-particle models [69, 176, 177, 186], linear, Freundlich, Langmuir models, Polanyi-Dubinin-Manes model [71, 147], porevolume diffusion model (PVDM), pore-volume and surface diffusion model (PVSDM) $([119,120,151])$, poly-parameter linear free energy relationship $[72,156]$ and film-pore mass transfer (FPMT) [56].

The use of these models is dependent on the laboratory experimental framework. Some of the models have significant limitations, e.g. PFO and PSO models, which only considers adsorption step on the active sites and predicts the internal diffusion while ignoring the external diffusion. In the use of linear, Freundlich, Langmuir isotherms models, assumption is made that there is a local equilibrium between the contaminated aqueous medium and microplastics, an assumption that may be misleading [156]. More refined models such as poly-parameter linear free energy relationship and novel FPMT recently developed and were reported to be the best so far $[60,156]$. In their study, using the novel FPMT model, phenomenological $\mathrm{Sr}^{2+}$ sorption onto spheroids primary microplastics was achieved [60].

\subsection{Adsorption mechanism}

Microplastics consist of various types of polymers (e.g. polypropylene, polyethylene, polystyrene, etc.) having different surface structures and, therefore, different affinities to pollutants. The adsorption generally involves the incorporation of toxic chemicals into the pitted surface microplastics while the adsorption capacities are influenced by weathering processes [68] and plastic type. Plastic types play an important role on the type of toxic chemicals sorped from the environment. For example, an in situ adsorption experiment demonstrated greater sorption of PCBs to PE pellets than PP pellets [111], laboratory adsorption experiments showed higher distribution coefficients of PAHs for PE than for PP $[82,83,85,159]$, and two alkylbenzenes sorbed more strongly to PVC than to PE [185] and for heavy metals showed higher distribution coefficients of $\mathrm{Zn}$ for PS than for PVC while vice versa for Cu [10]. Also, the understanding of the mass transfer kinetics in the adsorption process is important to evaluate and predict the adsorption behaviours of microplastics. The sorption kinetics includes three mass transfer steps: (a) the diffusion of sorbate across the liquid film around the sorbent, (b) the diffusion of sorbate inside the sorbent and (c) the adsorption on active sites [60]. However, there are three plausible mechanisms by which chemicals are adhered onto microplastic particles include (1) adsorption onto microplastics as hydrophobic adsorbents, (2) biofilm growth assisted and (3) plastic additives and related chemicals contained with resins. 


\subsubsection{Hydrophobic adsorption of chemicals}

Microplastics tend to be more hydrophobic because they exhibit low polarity on their surface. This enables the hydrophobic (water hating; immiscible in water) adsorption of chemicals onto their surfaces from seawater. They act like hydrophobic adsorbents in the environment (e.g. sea). Microplastics are less dense than water and thus accumulate most in surface microlayer (SML) of sea water. Lipid-loving chemicals like POPs (including polychlorinated biphenyls PCBs, polycyclic aromatic hydrocarbons (PAHs) and organochlorine pesticides such as DDT and DDE) have the right characteristics to adsorp and concentrate on the plastics hydrophobic surface forming a micelle shape-like structure. The extent of adsorption can be determined using the adsorption partition coefficients $\left(\mathrm{K}_{\mathrm{pw}}\right)$ calculated as the ratio of pollutant concentration adhered onto microplastics to the environmental medium (e.g. water) in equilibrium, i.e. $K_{\mathrm{Pw}}=C_{\mathrm{p}} / C_{\mathrm{w}}$ Eq. (1), where $K_{\text {pw }}\left(L_{\text {water }} / \mathrm{kg}_{\text {plastic }}\right)$ is the partition coefficient of the chemical from water to microplastic and $C_{p}$ ( $\mathrm{mol} / \mathrm{kg}_{\text {plastic }}$ or $\left.\mathrm{mg} / \mathrm{kg}_{\text {plastic }}\right)$ and $C_{\mathrm{w}}\left(\mathrm{mol} / \mathrm{L}_{\text {water }}\right.$ or $\left.\mathrm{mg} / \mathrm{L}_{\text {water }}\right)$ are the concentrations of the chemical in microplastic and water, respectively [34]. A simple schematic of the adsorption mechanism process using PAH (phenathrene) is presented in Fig. 3.

Microplastics as stated earlier have low polarity on its surface due to electrostatic interactions and $\mathrm{pH}$ of point of zero charge $\left(\mathrm{pH}_{\mathrm{pzc}}\right)$ being lower than most environmental pHs $[94,125,190,199]$. The low polarity (becoming more negative) exhibited by microplastics could also be responsible for aqueous metal ions adsorption on their surfaces. Aqueous metal ions are positively charge $\left(\mathrm{M}^{+}\right)$and bind by electrostatic attraction to the negatively charged groups on the surface of the plastic and neutralize their charge, forming also micelle shape-like structures (shown in Fig. 4) similar to the ones presented in Fig. 3a. Irrespective of adsorption medium (whether it is soil, sediment, water or air), the mechanism of adsorption is thought to follow the same principle, although the binding form might vary with different plastic types and metal ion type (cationic or anionic). Detailed studies are, however, required to unravel how aqueous anionic metal ion such as arsenic (As), selenium (Se), chromium VI [Cr(VI)], molybdenum (Mo) and boron (B), which binds on surface of plastics.

The accumulation or adsorption of toxic chemicals on microplastics in the natural environment takes longer time than in a controlled laboratory experiment [43]. The reason is that while plastics continue to degrade, oxygen groups are generated increasing the polarity and also the surface area is changed, which increases the porosity and charge, making the plastics surface more reactive $[67,81,111,47$, $2]$, and therefore, long equilibration times are required $[35,82,137]$. However, the case is different for laboratory experiment where equilibrium is reached rapidly. Holmes et al. [67] in a laboratory experiment showed that the absorption of trace metals such as $\mathrm{Pb}, \mathrm{Co}, \mathrm{Ni}, \mathrm{Cd}, \mathrm{Cu}$ and $\mathrm{Cr}$ onto virgin polyethylene pellets in trace metal-amended seawater is rapid with equilibrium partition coefficients of up to about $50 \mathrm{ml} / \mathrm{g}$ in Langmuir or Freundlich fashion.

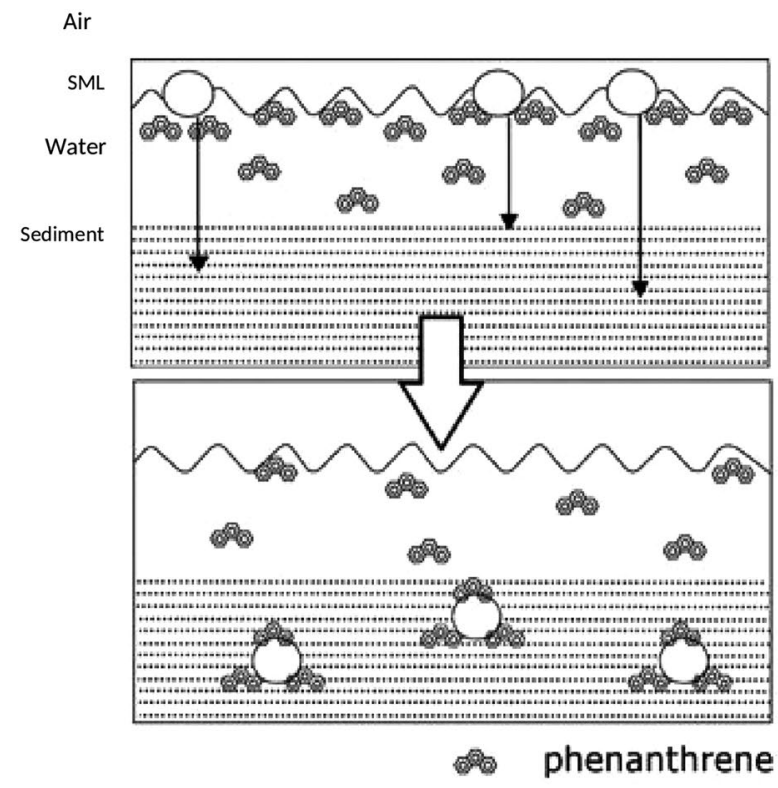

(a)

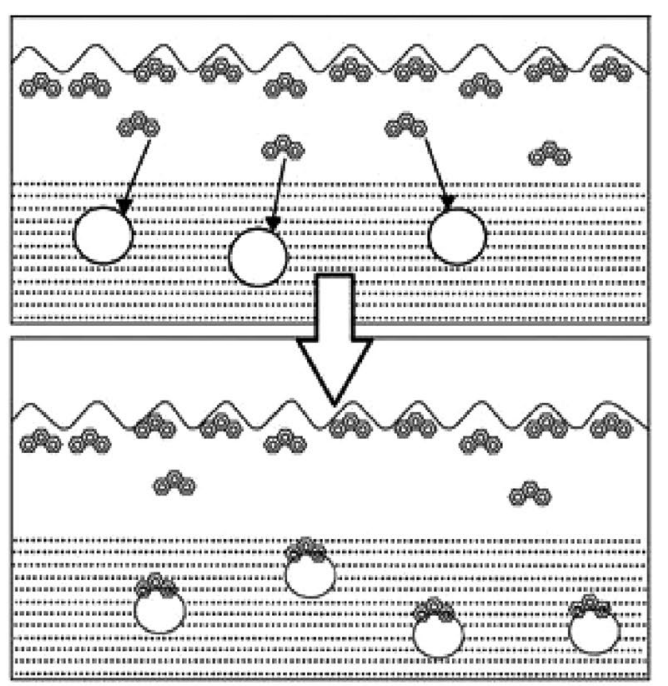

plastic particle

(b)

Fig. 3 Mechanisms of transfer of contaminants when: a Clean microplastics are presented in SML, and $\mathbf{b}$ clean microplastics are presented in sediment 


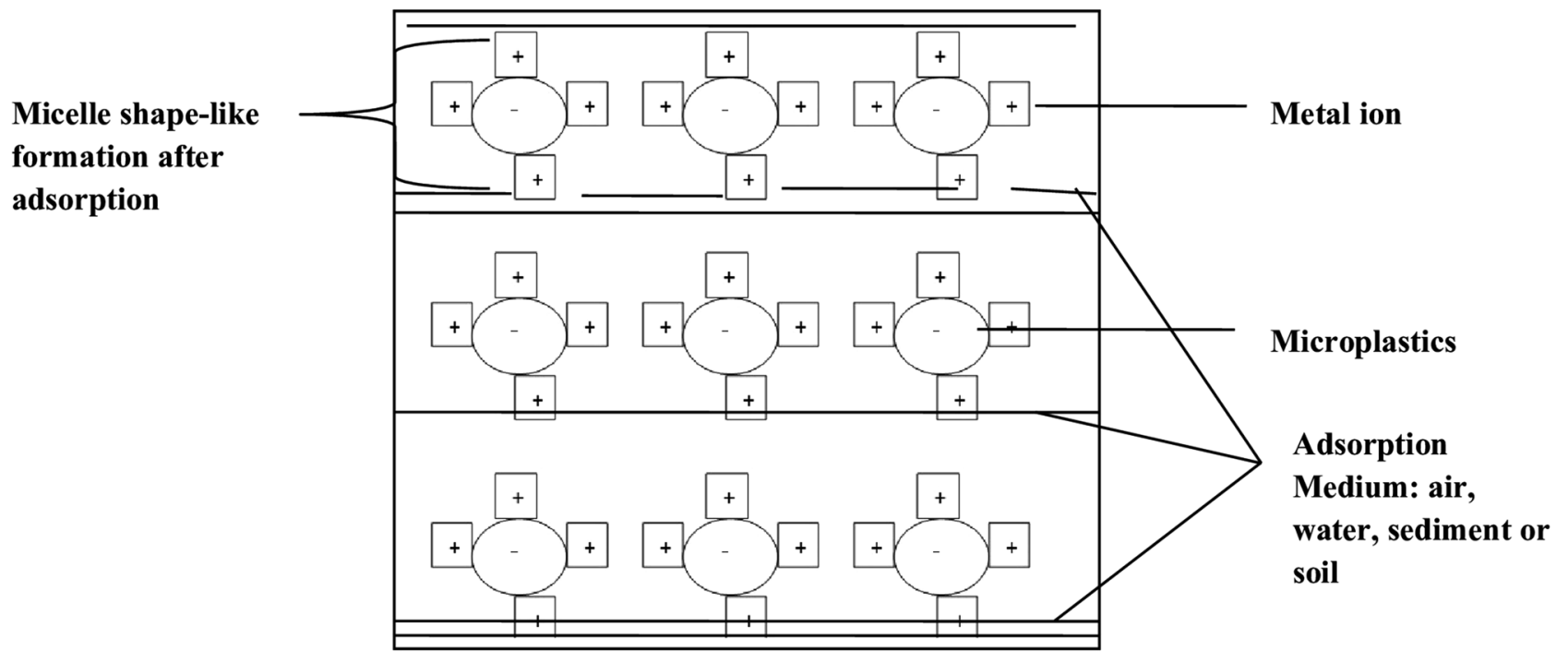

Fig. 4 Schematic of adsorption of metal ion onto microplastic

\subsubsection{Biofilm growth assisted}

A review study on metal immobilization by biofilms conducted by van Hullebusch et al. [167] revealed that biofilm is a sorbent for metals. Biofilms are formed by microorganism through a process called quorum sensing (QS). QS is known to control gene expression in which microbial cells form matrix of extracellular polymeric substance (EPS) by adhering to each other on a living or non-living surfaces $[77,140,144,161]$. Biofilms are ubiquitous in nature and commonly occur on hard surfaces submerged in or exposed to an aqueous solution $[149,152]$ such as microplastics accumulating in SML of sea water. The EPS may act like a ligand and by chelation may bind metals to control their mobility, distribution in the aqueous environment or directly use them within the cell [133].

The biofilm formation processes begin within seconds of first contact of virgin microplastic particles and ambient water [19, 105]. A graphical illustration of biofilm formation process on microplastic surface is presented in Fig. $5 \mathrm{a}$ while in Fig. 5b, a biofilm attached to the surface of microplastic (in the micrograph; the plastic is HDPE) incubated in waste water for 6 month studied using scanning electron microscopy (SEM) is presented. The formation process can be monitored under SEM; however, under different environmental conditions/ factors as well as plastic type, different micrographs will be generated. $[130,131]$ pointed that biofilm growth is largely depended on light and temperature, as well as on the trophic state of the media. Characterizing chemical composition of biofilm which can be achieved by Fourier transform infrared (FTIR) spectroscopy [122], SEM-EDS [172], microfluidics [46, 139] and XRD [138] may also be used. This in turn may provide insights into microbial-microplastic-toxic chemical interactions under different conditions, since community composition influences metal sorption [116, 143].

Biofilm can increase the immiscibility (lesser polarity; high hydrophobicity) of plastic surface in water and through pitting of microbial cell, which also increase the surface area $[104,112,132,196]$. This in turn increases sorption sites on plastic surface for metals adsorption [133]. However, a study by [32] on the response of a biofilm bacterial community to UV radiation suggests that formed biofilm on plastic surface may block UV light and therefore slow down the plastic degradation processes,
Fig. 5 a Biofilm formation on the surface of microplastic [19]. b Scanning electron micrograph showing a biofilm attached to a microplastic [63]

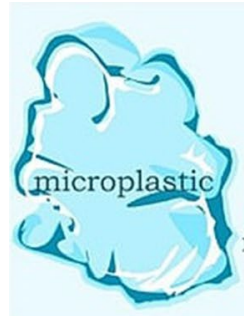

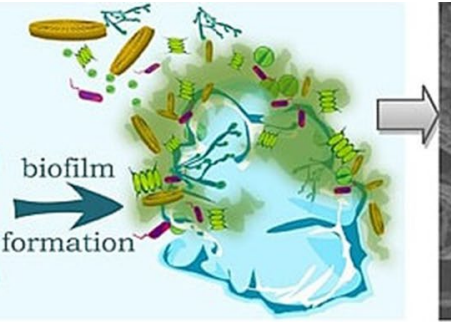

(a)

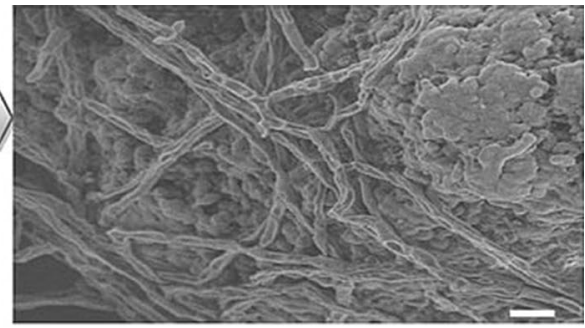

(b) 
thus reducing the surface area and sorption sites of plastics. Hence, studies will be required to understand better the relationship between growth of biofilm and plastic degradation as conveyor of metal accumulation in the environment. Furthermore, following the high estimate (1000-15,000 metric tons) of microbial biomass reported to be associated with global plastic debris presented in a study by Mincer and his colleagues in 2016, it became more obvious that biofim may be playing a crucial role in toxic chemical transports by microplastics [112], and therefore, studies on microplastics serving as a vector for toxic chemicals in aquatic habitats should include biofilm as variable [133]. This is of ecotoxicological concern as literature data pointed out that biofilm is the reason that some animals are attracted to plastic as a source of food [143], thus potentially contaminating the base of the food chain.

Limited studies to have examined the effect of biofilm growth on adsorption of toxic chemicals on microplastics surface are based on observation through microscopic techniques rather than mechanistically driven [31, 109, 132]. One study conducted on San Francisco Bay found that metal such as nickel (Ni), aluminium (Al) and zinc ( $\mathrm{Zn}$ ) accumulation on plastic (low-density polyethylene; LDPE and polylactic acid; PLA) is attributed to biofilm growth. Furthermore in the study, data suggest that difference in plastic shape, the medium can result in variation in growth patterns of biofim and biofouling communities [133]. Other studies have shown that community composition influences metal sorption [143] and sorption properties of biofilm can depend on season and biofilm maturity.

Finally, metal composition within a biofilm can increase sorption by organic pollutants. Ions within a biofilm are reported to be more labile than ions bound to ion exchange polymers and can be used as nutrients by cells within biofilms. Again, these processes must be explored further before accurate estimates can be made regarding the potential for plastic to accumulate, transport and release heavy metals. Majority of kinetic studies on the influence of biofilm have ignored the attachment of chemicals such as HOCs $[91,186]$. Further biofilm studies for these types of chemicals are warranted.

\subsubsection{Plastic additive and chemicals in resins}

Another plausible mechanism may be from additives used in plastic production and related chemicals contained with resins. This mechanism is often common with thermosetting plastics in which the term "resin" is loosely applied. Plastic contains many synthetic chemicals as additives. These additives may vary with different polymer types. In 2000, different plastic additives reported were $>300$ [13], while the groups of plastic additives with examples of hazardous chemicals have been reviewed previously [61]. However, most common additive is the formalaldehyde, bisphenol A (BPA) and phthalates. These chemicals are added to plastics to make it hard, durable, flexible and long lasting. Unfortunately, they are transported with microplastics in the environment and are potentially harmful to wildlife and humans. The International Agency for Research on Cancer (IARC) classified formaldehyde as carcinogen category $1 \mathrm{~B}$ while BPA may disrupt hormone and reproductive systems, including abnormal penis development in men [41]. The molecular size is a key property of the additive when evaluating how fast it migrates through and out of the plastic. The smaller the additives, the faster they will migrate.

\subsection{Desorption mechanism}

The desorption reactions of toxic chemicals from microplastics in the environments control their concentrations in solution and affect their bioavailability, leaching and toxicity. Toxic chemicals are often attached on microplastics surfaces by physical interactions (i.e. physisorption, involving non-covalent bonds) and are held by weak forces or interactions such as hydrogen bond, van der waals and cavity formation [57]. Therefore, desorption processes may occur easily. Desorption processes of pollutants from microplastic are simply referred to the process in which the pollutant manoeuvre from the initial position in the polymeric system to the polymer outer surface and then to the release medium, viz. soil, sediment, water or animal/human body. The processes may vary by the redox state of the adhered metals, desorption capacities and the binding energies of their adsorption sites. These reactions may be affected by many factors, such as $\mathrm{pH}$, type of plastics, salinity, presence and concentration of organic and inorganic ligands in the release medium. If the release medium is soil or sediment, the components responsible for trace element sorption include, soil humic substances, carbonates and inorganic components (variable charge minerals and phyllosilicates) [173]. A detailed summary of these driving factors is shown in Fig. 6.

Desorption or release mechanisms of toxic chemicals are unclear and remain relatively unexplored by researchers. Release of pollutant from a microplastic particle to another medium is usually subdivided into two mass transfer processes, viz. internal mass transfer (IMT), which involves internal diffusion within the microplastic particle, and external mass transfer (EMT), which involves transfer from the microplastics to the plastic particle surface in the release medium (often aqueous) $[127,157]$. In an aqueous system (involving microplastics and toxic chemical) at equilibrium, the EMT of a chemical 
Fig. 6 Summary of factors that may influence pollutant release kinetics
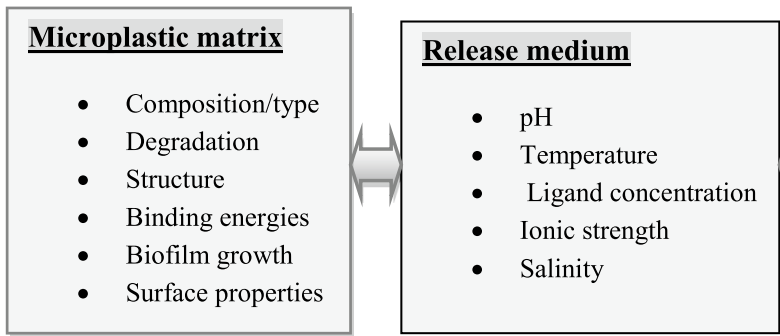

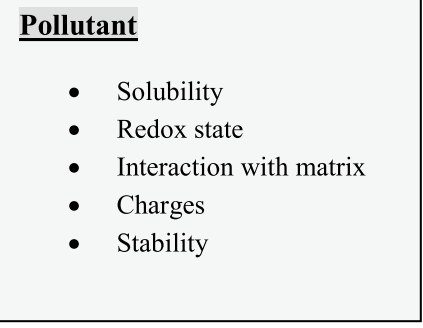

from plastics always occurs in such a direction that the actual concentration ratio $\left(C_{p} / C_{w}\right)$ approaches the value of $\mathrm{K}_{\mathrm{pw}}$ (i.e. if $\mathrm{C}_{\mathrm{p}} / \mathrm{C}_{\mathrm{w}}>\mathrm{K}_{\mathrm{pw} \text { ), }}$ and then, desorption from the plastic to water takes place [34]. As pointed, equilibrium (or near equilibrium) situations often occur in closed or controlled systems, but can also occur in systems where the phase transfer occurs much quicker than other disturbing processes (e.g. degradation of the chemical) [34].

When an adsorbed pollutants have been transported to a new environment and come in contact with a new material, e.g. non-polluted sediment or soil, there may be desorption of pollutant from the microplastics onto organic or inorganic ligands present in the sediment and soil matrix (Fig. 7). [159], reported desorption of PAH (e.g. phenanthrene as an example used in the study) from microplastic surface to organic matter in sediment on the basis of concentration gradient. Another basis for increasing desorption in aqueous medium is the salinity level of the medium. One study recently found that there was a clear trend of decreasing sorption of DDT with increasing salinity of the aqueous medium [3]. Generally, as pointed out by [8], that organic compounds becomes less soluble as salinity level rise and partitioning of organic chemicals into other phases are affected by the salt content in aqueous phase. However, desorption of phenathrene was not affected by salinity [4]. More study will be needed to understand how salinity affects desorption of organic pollutants from microplastics.

Assuming a mass balance in a batch study, desorption of toxic chemicals from virgin plastics pellets may be studied using the pseudo-first-order model [159] in which the mass flux is proportional to the concentration difference across the aqueous boundary layer. Typically, Fickian diffusion is the rate limiting step [156] and provides the fundament for description of pollutant release from microplastic surface [192], based on concentration gradient, release distance and biofilm growth [96]. In this context, Fickian diffusion refers to the pollutant transport process in which the microplastic relaxation time $(\mathrm{tr})$ is much greater than the characteristic medium diffusion time $\left(t_{d}\right)$, i.e. $t_{r}>t_{d}$. A graphical illustration of possible desorption/release mechanism of pollutant from microplastic matrix is shown in Fig. 7.

\section{Implication of microplastics-toxic chemical interaction}

There are many reports already on the abundance of microplastics in environment matrices, viz. water, soil and more recently air. As already established, their effects in

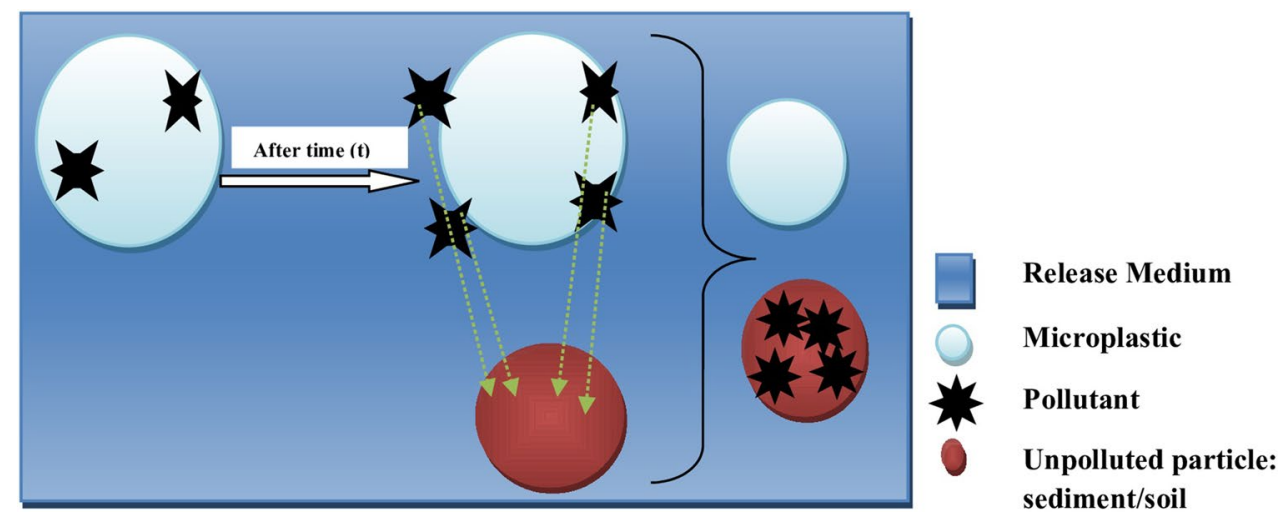

Figure 7 Graphical illustration of possible desorption/release mechanism of pollutants from microplastic surface onto clean/ unpolluted particle. The adsorbed pollutant (black star) on the basis of concentration gradient, release distance and biofilm growth will migrate and adsorb onto the clean sediment (purple ball) rich in organic material (ligands). In sediment/soil, such ligands include humic and fulvic acids, root exudates and nutrients 
the environment could be doubled by their interaction with toxic chemicals. In this section, the implications of that interaction are discussed under sections of environment and human health.

\subsection{Environment}

The environment literally means the surrounding, which extends from the elements of the microcosm, within every community to the cosmos of the atmosphere and universe. However, we shall only consider the implication of microplastics in three environmental media, viz. air, soil and water.

\subsubsection{Air}

The Earth's atmosphere is considered as air, in which living things live and breathe. Clean air happens to be the most important matter required by living organism for survival. Therefore, when air is contaminated, living organism is at risk of death. There are many studies available on air pollution regarding suspended particulate matter (SPM), but concerning the presence of suspended microplastics in air has gained little attention. Limited evidence is available on the transport of microplastics in air $[1,14,28,29,86,100$, 200]. These studies have identified fibrous microplastics (Fig. 8) from atmospheric fallout at various concentrations both in indoor and outdoor air as well as in urban and remote areas. These findings suggest that humans may be at risk of potential exposure through inhalation or by contact through skin. Detailed review on available information regarding airborne microplastics has been conducted recently [40]. However, researchers should explore how different microplastic types and shape, whether it is more of a film or fibre or fragment, affects the movement of microplastics in air. It might assume that a film with more surface area would travel farther than a fragment, but there is no evidence yet.

Generally, urban areas have higher distribution of atmospheric microplastics as reported by Dris and his colleagues in 2016, which is not surprising as urban area are known to experience high anthropogenic activities. From the urban areas, microplastics can be transported in air for more than 50 miles to remote areas. One study was recently published regarding airborne microplastics in a remote mountain catchment [1]. The authors reported relative daily counts of 249 fragments, 73 films and 44 fibres per $\mathrm{m}^{3}$ in pristine mountain catchment (French Pyrenees), of which they came from neigbouring densely populated areas up to $95 \mathrm{~km}$ far north as revealed by air mass trajectory analysis [1]. A study by [28] investigated atmospheric fibres in indoor and outdoor air and revealed significant indoor concentrations of $1.0-60.0$ fibres $/ \mathrm{m}^{3}$ while lower concentrations of $0.3-1.5$ fibres $/ \mathrm{m}^{3}$ were reported for outdoor air. The suspended microplastics in indoor air later settled and accumulated in the indoor settled dust (190-670 fibres/mg), which can be re-suspended in air when the dust is perturbed.

The literature reviewed has shown that microplastics are present in air at varying concentrations controlled by the anthropogenic source and humans may be breathing it [38]. This newly found exposure route of human to microplastics can be a call of concern, judging from the importance of air for human survival. Therefore, more detailed study on the distribution and potential ecological risk posed by airborne microplastics in the environment is required.

\subsubsection{Soil}

One essential component of terrestrial ecosystems is soil, and they experience strong pollution pressure. Microplastic contamination of soils is being increasingly documented, with potential consequences for soil biodiversity and function [49, 99, 108, 145, 197, 198]. However, the ecological impacts of microplastics in soils have been well reviewed $[25,203]$.

The impacts of soil microplastics can be on soil microorganisms, animals as well as plants growing on them. Reports suggest that the impact on soil micro-organisms as well as antibiotic resistance genes (ARGs) may be positive or negative depending on particle type and concentrations. [98] found that PP particles at certain percentage in soil ( $7 \%$ and $28 \%$ ) have positive effects on soil microbial activity while contrasting results were recorded for other plastic types at smaller concentrations
Fig. 8 Fibrous microplastic observed in atmospheric fallout. (Source: Gasperi et al. [50]

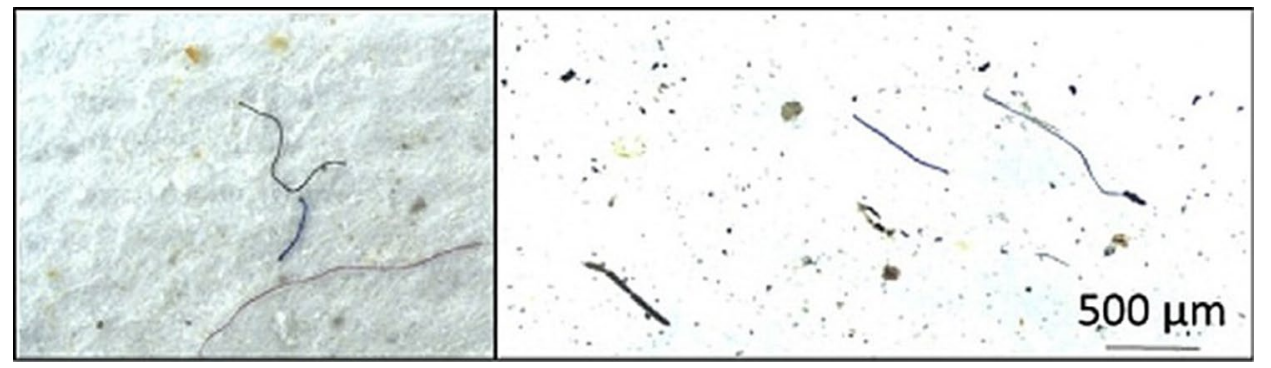


(0.05-0.4\%), viz. PA, polyester and PS $[2,25]$. Furthermore, ARGs which have been gaining increasing attention recently due to their potential adverse effects on human health are affected by microplastics. Recently, the time of retention of ARGs in soil ecosystem has been shown to increase by the presence small concentration (0.1\%) of microplastics (particularly PP) [155]. Conclusively the behaviour/activity of soil micro-organisms may vary according to plastic types, shape, size and concentration of microplastics present in the soil. However, these observations are still sketchy; therefore general conclusion cannot be drawn on the toxicity of microplastics in soil based on their type, shape and quantity. Also, studies have shown that soils microbial activities are affected toxic chemicals such as heavy metals in soil $[171,187,188]$; therefore in tandem with microplastics they may cause combined effects on soil microbial community. Research is required to investigate how microplastics in synergy with toxic chemicals affect microbial movement or facilitates the transmission of ARGs in soil environment.

In terms of soil animals, there is only little information available on effects of microplastics pollution. Few studies have examined soil invertebrates, such as nematodes [92], collembolan [78, 202], oligochaeta (e.g. earthworms) [201] and isopods [89]. The toxicological effects of microplastics on these invertebrates are dependent on the size and particle concentration or level of exposure [87, 92, 201]. [92] examined the effects of different PS micro-particle sizes $(0.1,0.5,1.0,2.0$ and $5.0 \mu \mathrm{m}$ ) on nematode (Caenorhabditis elegans) for 3 days and found strongest toxicity of $1.0 \mu \mathrm{m}$, due to the fact that nematodes easily accumulate moderate-sized microplastics in soil [203]. Also, the toxicity significantly downregulated the expression of unc-17 and unc-47 genes, reflecting damages to cholinergic and GABAergic neurons in nematodes [92]. However, soil oligochaeta and lumbricidae are affected by the concentrations of microplastic particle in the soil medium.

Studies by Zhu et al. [201] and [70] demonstrated that high concentrations of PS (10\%) and PE (28-60\%) microplastics particle negatively affect and inhibit growth and survival of Enchytraeus crypticus (oligochaeta) and Lumbricus terrestris (earthworm), respectively, in soil. Furthermore, biodegradable microplastics from starchbased biodegradable films in soil (1\%) had more effects on earthworm growth than conventional low-density PE films [129]. Zhu et al. [203] pointed that this observation is possibly due to the main composition of biodegradable plastics (i.e. polyethylene terephthalate (PET) and polybutylene terephthalate), which might be more toxic than PE. Microplastics pollution in soil also affects soil collembolan as revealed by recent studies [78, 202]). For example, exposure of Folsomia candida in soil to PVC (0.1\%) and PE
(0.1-1\%) microplastics revealed significant inhibition of growth and reproduction of this animal $[78,203]$. Also in both studies, gut bacterial community was significantly altered by the microplastic pollution in the soil. Only one study was found regarding the effects on microplastic pollution on soil isopod. Recent study by [89] examined their behaviour to feeding and how they reserve energy after 14 days of exposure to PE (0.4\%) microplastics and found no significant effects on the animal at the end of the experiment, thereby suggesting no or little hazardous effect of PE microplastics. Detailed investigation could be for longer periods and varying concentrations of microplastics/toxic chemicals of combined effects of different microplastics types and toxic chemicals on soil animals (invertebrates); growth or survival, feeding behaviour and energy reserve should be carried out to gain more insight on the effects of the tandem interaction of microplastics-toxic chemicals.

The concern of microplastics polluted soil polluting plant is based on the tendency of plant accumulating them through uptake $[39,40]$. This potential bioaccumulation can adversely affect the growth of the plant and food quality. Fluorescent microbeads can be used to investigate the possibility of plant uptake of microplastics [203] while model such as bioaccumulation/concentration factors (BCF) can be used to assess the extent of accumulation. The hypothesis for the uptake is that plant cell wall and membrane barriers can be by-passed by small-sized microplastics [203]. Few evidences existed concerning uptake of nanoplastics $(<100 \mathrm{~nm})$ and microplastics $(0.2 \mu \mathrm{m})$ by plant $[5,95]$ and the effects on plant growth $[5,129]$ demonstrated that through endocytosis, nanoscale fluorescent PS beads could enter tobacco cells. [95] assayed edible plants grown in China found that fluorescent micro-PS beads were transferred from the soil to the plants. These findings clearly showed the potential risk of consuming microplastic by human through plant web chain.

Meanwhile, their presence in plant can cause the plant to have a poor or stunted growth, effect which correlated strongly with biodegradable microplastics probably due to its composition (containing PoTSs, i.e. PET and polybutylene terephthalate) than conventional microplastics. [129] found out that biodegradable microplastics have stronger negative effects on the growth of wheat and the fruit biomass than conventional PE microplastics. However, the toxicity of microplastic pollution (especially with adhered toxic chemicals) to plants should be investigated. Plants are known to bioaccumulate toxic chemicals, which have been used well in phytoremediation studies $[73,75,164$, 189]. However, the uptake of microplastics by plant could be beneficial for soil as plant is serving as a potential phytoremediator [39]. These concepts will be needed to be explored for clearer understanding of the potentiality of using plant as a phytoremediator of microplastics in soil. 


\subsubsection{Water}

Microplastic pollution of aquatic ecosystem has been intensively studied as compared to soil ecosystem or in the atmosphere. Microplastic pollution is listed among the major perceived threats to biodiversity due to its abundance, durability and persistence in the marine environment [51]. The impacts of microplastics pollution in aquatic ecosystem have been extensively reviewed and documented $[15,30,51,55,147,163]$. These reviews provided a comprehensive documentation defining the current state of knowledge of microplastics: the provenance, fate and externalities of their presence in our marine ecosystem and interaction with marine organisms. However, marine organisms generally interact with microplastic debris either via entanglement or ingestion. From reports, 220 species contaminated with microplastics were found to be through ingestion while 580 contaminated species were probably through entanglement $[107,163]$, totalling 800 species indentified, including marine mammals, fish, invertebrates and fish-eating birds. Detrimental effect of contamination includes particle accumulation in organism digestive tract and possible translocation from intestinal tract to the circulatory system or surrounding tissue $[55,107,147]$.

\subsection{Toxicity to human}

Humans may inject microplastics directly (via consumption of microplastic contaminated water, soil or salt) or indirectly via trophic transfer (e.g. via consumption of microplastic contaminated seafood and plant) or inhaling airborne microplastics. The greatest exposure might be through seafood consumption, serving as major protein source and as the sea happens to be a hot spot for plastic debris pollution. Food and Agricultural Organization in their 2016 report on "the state of the world fisheries and aquaculture" reported that in 2015 alone, $6.7 \%$ of human protein and $17 \%$ of animal protein consumed globally were from seafood [42]. However, by implication of having fibrous microplastics in air from atmospheric fallout, they can enter the body through mouth, nose or skin [40], particularly fibrous microplastics that did not meet the criteria for airborne fibres, i.e. the length should be greater than $5 \mathrm{~mm}$, with a diameter of less $3 \mathrm{~mm}$ and an aspect (length-to-diameter) ratio greater than 3-1 [180].

Generally, the health effects depend on concentrations of microplastics exposed to. Currently, there is no accurate amount estimated for microplastics injected by humans via food or air, due to data gap and limited evidence. However, an estimate for total microplastic intake by human annually via salt consumption was predicted by [191] to be at most 37 particles per individual while approximately 11,000 plastic particles were estimated to be consumed by a top European shellfish consumer annually $[79,80,166$, 191] while an estimate of $80 \mathrm{~g}$ per day was predicted for microplastics intake via plant (fruits and vegetable) [39]. The implications of consuming microplastics are currently unknown; however, impact may potentially be particle (via particle localization), chemical (with associated toxic chemicals) or microbial. The plausible effects of microplastics on human health have been critically discussed (see [183]). [183] critically assessed potential level of exposure of particle, chemical and microbial hazards associated with microplastics to inform understanding of microplastics uptake, internalization, impacts and potential adverse human health outcomes.

The particle toxicity occurs when the critical mass of microplastics is localized causing immune response from the body, of which the body cannot do much about. There are no reports of particle toxicity of microplastics to human perhaps due to the ability of human disposing $>90 \%$ of ingested plastics via faeces $[147,183]$. How they are retained in or cleared from the body are depended on some factors which include size, shape, length, polymer type and additive chemicals of microplastics [107]. For example, in terms of length, longer fibrous microplastics have been reported to biopersist and resist being cleared from the lungs $[128,178]$ while shorter ones are easily cleared. The biopersistence can cause lung inflammation and potentially leads to secondary genotoxicity following the excessive and continuous formation of reactive oxygen species (ROS) [54].

The general paradigm for chemical effects follows the fact that microplastics can sorp toxic chemicals such as heavy metals and HOCs on its pitted surface, thereby conferring exposure of humans to associated toxic chemicals. Detrimental pulmonary outcomes could then ensue following desorption of associated contaminants leading to primary genotoxicity, reproductive toxicity, carcinogenicity and mutagenicity [54, 97]. For example, stable and unstable DNA lesions may arise after metabolism of fibrous MP-associated PAHs [59]. Few studies have assessed the relative contribution of microplastic exposure to additives or chemicals found in organisms versus alternative exposure pathways $[56,147]$.

Microbial effects followed the ability of micro-organisms forming biofilms on microplastics surface when exposed in aqueous medium. Harmful human pathogens such as strains of Vibrio spp have been isolated in formed biofilm on microplastics $[88,196]$. Also, as one of the plausible mechanisms of toxic chemical transport by microplastics, formed biofilm can include heavy metals and HOCs. [133] found biofilm growth assisted in metal (Ni, $\mathrm{Al}, \mathrm{Zn}$ ) accumulation on microplastics surface (LDPE and PLA). The relationship between and toxic chemicals can be problematic as microbes have the capacity to metabolize 
them [168]. This in turn can have knock on effects for the host, compromising immunity and stimulating inflammation in the body [18]. Oxidative stress and inflammation have a key role in the pathogenesis of inhaled pollutants and also modify local conditions, which potentially influence the microbiome [183].

\section{Conclusions, knowledge gaps and future area of research}

In the last 15 years, there has been an increased interest on microplastics pollution by researchers, which has brought about an expanding knowledge on the subject. Reports have confirmed that microplastics serve as a vector for toxic chemicals (heavy metals and HOCs) transport in the environment and when ingested with potential migration in the body. The conclusions from this study will be presented under different sections as presented in the review;

1. Conclusions on quantified concentrations of toxic chemicals adhered on microplastics surface.

- The toxic contaminant concentrations varied among locations (with concentrations reaching up to $38,800 \mu \mathrm{g} / \mathrm{g}$ for heavy metals to as high as $101,000 \mathrm{ng} / \mathrm{g}$ for organic pollutants), indicating that the contamination represents a local problem or the surroundings. Microplastic particles from heavily polluted areas contain higher levels than those from less polluted areas.

- Concentrations are controlled by discolouration of microplastic with yellowed (discoloured) ones generally having higher concentration. Therefore, degradations stage of plastic plays an important role on concentration of sorped contaminant.

- Additives used in plastics (more than 300) are PoTSs and can migrate internally to plastic surface and externally from the plastic surface. Additives have the tendency to increase concentrations on toxic chemicals sorped from ambient environment.

- Generally, quantification of toxic chemicals from microplastic surface is mostly done using spectroscopic techniques following weak acid (e.g. 10\% $\mathrm{HNO}_{3}$ ) or aqua regia extraction for toxic metals while soxhlet-assisted $n$-hexane, methanol $(\mathrm{MeOH})$ or dichloromethane (DCM) extraction for organic pollutants.

- Twelve metals (Al, As, Cd, Cr, Co, Cu, Fe, Mn, Ni, Pb, $\mathrm{Ti}$, and $\mathrm{Zn}$ ), one halogen ( $\mathrm{Br}$ ) and fifteen groups of organic pollutants (PAHs, PCBs, DDTs, HCHs, chlordane, mirex, hexachlorobenzene, hopanes, PBDEs, PFC/PFA, aliphatic hydrocarbons, BPA, NPs and OPs) have generally been quantified from different locations up till now.

- Few studies have been reported concerning African marine environment (Ghana, Mozambique and South Africa) and none regarding Nigerian environment.

2. Conclusions on adsorption and desorption mechanism

- Currently, there is no accurate information on adsorption and desorption mechanisms of toxic chemicals onto/from microplastics. However, plausible adsorption mechanisms include hydrophobic adsorption, biofilm growth-assisted adsorption and additives.

- Refined models such as poly-parameter linear free energy relationship and novel film-pore mass transfer (FPMT) recently developed were reported to be the best so far for studying adsorption mechanism of toxic chemicals.

- The partition or sorption coefficient $\left(\mathrm{K}_{\mathrm{pw}}\right)$ is of tremendous importance for understanding the sorption/desorption behaviour of a chemical to/ from microplastics in water at equillibrium.

- The following factors influence desorption mechanism kinetics; microplastic matrix: composition/ type, degradation, structure, binding energies, biofilm growth and surface properties; release medium: $\mathrm{pH}$, temperature, ligand concentration, concentration gradient, ionic strength and salinity; pollutant: solubility, redox state, interaction with matrix, charges and stability.

3. Conclusions on Implications

- Microplastics can be transported up to $95 \mathrm{~km}$ through air from their source to a new environment. Anthropogenic activities influence the amount of microplastics suspended in air.

- Microplastics can be suspended in indoor atmosphere, and thus, inhabitants may inhale microplastics from indoor air.

- Humans may inject microplastics directly (via consumption of microplastic contaminated water, soil or salt) or indirectly via trophic transfer (e.g. via consumption of microplastic contaminated seafood and plant), inhaling or having direct skin contact to airborne microplastics.

- It is clear that marine and soil organisms can interact with microplastics via ingestion or entanglement and that laboratory experiments show that this can result in harm.

- Impact of microplastics on soil microbial community, animals and plant is depended on particle type, concentrations and size. 
- Plants can accumulate microplastics from soil, and laboratory experiments show that this can result in poor growth of the plant. Biodegradable microplastics have stronger negative effects on plant growth when compared to conventional microplastics.

- The implications of consuming microplastics by humans are currently unknown; however, impact may potentially be particle (via particle localization), chemical (with associated toxic chemicals) or microbial (through biofilm formation).

\subsection{Knowledge gaps and future area of research}

- No study has tried to expressly determine the source of toxic chemicals adhered to microplastics whether it is from the environment or from the plastic itself. Therefore, research is needed to understand/know the sources of toxic chemicals found on microplastics, whether they came from additives or from ambient environment during particle exposure or they came from the two means working synergistically.

- There is need for further studies elucidating role of microplastics as sinks or sources of metals and HOCs in the environment

- Could toxic chemicals be transferred between microplastics particles and tissue organisms? Further study is required to evaluate the possibility of toxic chemical transfer between the plastic carrier particles and the tissues found in living organisms.

- How do anionic metal ion such as arsenic (As), selenium (Se), chromium VI [Cr(VI)], molybdenum (Mo) and boron (B) binds on surface of plastics? Experimental studies are, however, required to unravel how aqueous anionic metal binds on surface of plastics.

- What role does biofilm formation play in adsorption of HOCs from ambient environment?

- Microplastics are now reported in the atmosphere. How many toxic chemicals are carried by airborne microplastics? This information is the basis for a precise risk assessment.

- What is the extent of microplastic pollution and what type in terms of shape, size, length and colour is most abundant in soil?

- What are the risks of microplastics pollution is soil posed to plant? One study has studied effects on wheat growth. However, there are still more questions to be answered such as the effects on many other plants (edible or non-edible), as well as how they are affected by microplastics types (in terms of colour and shape).

- Uptake of microplastics by plant has been demonstrated [95], and potential phytoremediator was dis- cussed [39]. However, the potentiality of using plant as a green cleaning method for microplastics in soil should be further explored for clearer understanding.

- It is already established that microplastics serve as vector for toxic chemicals transport in the environment. However, we need to get a better understanding about potential toxicity to plant, if plants while accumulating microplastics through uptake also accumulate toxic chemicals along.

\section{Compliance with ethical standards}

Conflicts of interest The researchers declare no conflicts of interest regarding the publication of this manuscript.

\section{References}

1. Allen S, Deonie A, Vernon RP, Gaël LR, Pilar DJ, Anaëlle $S$, Stéphane B, Didier G (2019) Atmospheric transport and deposition of microplastics in a remote mountain catchment. Nat Geosci 12:339-344. https://doi.org/10.1038/s4156 1-019-0335-5

2. Artham T, Sudhakar M, Venkatesan R, Madhavan Nair C, Murty KVGK, Doble M (2009) Biofouling and stability of synthetic polymers in sea water. Int Biodeterior Biodegradation 63(7):884-890

3. Awet TT, Kohl Y, Meier F, Straskraba S, Grün A-L, Ruf T, Jost C, Drexel R, Tunc E, Emmerling C (2018) Effects of polystyrene nanoparticles on the microbiota and functional diversity of enzymes in soil. Environ Sci Eur 30:11

4. Bakir A, Rowland SJ, Thompson RC (2014) Transport of persistent organic pollutants by microplastics in estuarine conditions. Estuar Coastal Shelf Sci 140:14-21

5. Bandmann V, Müller JD, Köhler T, Homann U (2012) Uptake of fluorescent nano beads into BY2-cells involves clathrindependent and clathrin-independent endocytosis. FEBS Lett 586:3626-3632

6. BBC (2018) Indonesian study into health risks of microplastics. http://www.bbc.com/news/science-environment-43913597. Accessed 09 Marc 2019

7. Boerger CM, Lattin GL, Moore SL, Moore CJ (2010) Plastic ingestion by planktivorous fishes in the North Pacific Central Gyre. Mar Pollut Bull 60:2275-2278

8. Borrirukwisitsak S, Keenan HE, Gauchotte-Lindsay C (2012) Effects of salinity, $\mathrm{pH}$ and temperature on the octanol-water partition coefficient of bisphenol A. Int J Environ Sci Dev 3:460-464

9. Brakstad OG, Bonaunet $\mathrm{K}$ (2006) Biodegradation of petroleum hydrocarbons in seawater at low temperatures $\left(0-5^{\circ} \mathrm{C}\right)$ and bacterial communities associated with degradation. Biodegradation 17:71-82

10. Brennecke D, Bernardo D, Filipa P, Isabel C, Joao C (2016) Microplastics as vector for heavy metal contamination from the marine environment. Estuar Coast Shelf Sci 178:189-195

11. Breysse PN (2017) Toxicological profile for polybrominated diphenyl ethers (PBDEs). Agency for Toxic Substances and Disease Registry 
12. Browne MA, Dissanayake A, Galloway TS, Lowe DM, Thompson RC (2008) Ingested microscopic plastic translocates to the circulatory system of the mussel, Mytilus edulis (L.). Environ Sci Technol 42:5026-5031

13. Cadogan DF, Howick CJ (2000) In Ullmann's encyclopedia of industrial chemistry. IndustrialChemistry. https://doi. org/10.1002/14356007.a20_43

14. Cai L, Wang J, Peng J, Tan Z, Zhan Z, Tan X, Chen Q (2017) Characteristic of microplastics in the atmospheric fallout from Dongguan city, China: preliminary research and first evidence. Environ Sci Pollut Res 24(32):24928-24935. https://doi. org/10.1007/s11356-017-0116-x

15. Carbery M, O'Connor W, Palanisami T (2018) Trophic transfer of microplastics and mixed contaminants in the marine food web and implications for human health. Environ Int 2(115):400-409. https://doi.org/10.1016/j.envint.2018.03.007

16. Carpenter EJ, Anderson SJ, Harvey GR, Miklas HP, Peck BB (1972) Polystyrene spherules in coastal waters. Science 178(4062):749-750

17. Carpenter EJ, Smith KL, Harvey GR, Miklas HP, Peck BB (1972) Plastics on the sargasso sea surface. Science 175:1240-1241

18. Cho I, Blaser MJ (2012) The human microbiome: at the interface of health and disease. Nat Rev Genet 13(4):260-270

19. Christoph DR, Annika J, Elena G, Dana K, Schmitt-Jansen M (2017) Impacts of biofilm formation on the fate and potential effects of microplastic in the aquatic environment. Environ Sci Technol Lett 4(7):258-267. https://doi.org/10.1021/acs. estlett.7b00164

20. Colabuono Fl, Taniguchi S, Montone RC (2010) Polychlorinated biphenyls and organochlorine pesticides in plastics ingested by seabirds. Mar Pollut Bull 60(4):630-634. https:// doi.org/10.1016/j.marpolbul.2010.01.018

21. Cole M, Lindeque P, Halsband C, Galloway TS (2011) Microplasticsas contaminants in the marine environment: a review. Mar Pollut Bull 62:2588-2597

22. Cole M, Lindeque P, Fileman E, Halsband C, Galloway TS (2015) The impact of polystyrene microplastics on feeding, function and fecundity in the marine copepod Calanus helgolandicus. Environ Sci Technol 49:1130-1137

23. Davison P, Asch RG (2011) Plastic ingestion by mesopelagic fishes in the North Pacific subtropical gyre. Mar Ecol Prog Ser 432:173-180

24. Day RH, Wehle DHS, Coleman FC (1985) Ingestion of plastic pollutants by marine birds. In Shomura RS, Yoshida HO (eds) Proceedings of the workshop on the fate and impact of marine debris. Honolulu, Hawaii: U.S. Dep. Commer., NOAA Tech. Memo. NMFS, pp 344-386

25. de Souza Machado AA, Chung WL, Jennifer T, Werner K, Anika L, Roland B, Matthias CR (2018) Impacts of microplastics on the soil biophysical environment. Environ Sci Technol. 52(17):9656-9665

26. Desforges JPW, Galbraith M, Dangerfield N, Ross PS (2013) Widespread distribution of microplastics in subsurface seawater in the NE Pacific Ocean. Mar Pollut Bull 79:94-99. https ://doi.org/10.1016/j.marpolbul.2013.12.035

27. DIRECTIVE 2008/56/EC of the European Parliament and of the Council. Official Journal of the European Union. https:// eur-lex.europa.eu/LexUriServ/LexUriServ.do?uri=OJ:L:2008: 164:0019:0040:EN:PDF. Assessed 23 Mar 2019

28. Dris R, Gasperi J, Mirande C, Mandin C, Guerrouache M, Langlois V, Tassin B (2017) A first overview of textile fibers, including microplastics, in indoor and outdoor environments. Environ Pollut 221:453-458

29. Dris R, Gasperi J, Saad M, Mirande C, Tassin B (2016) Synthetic fibers in atmospheric fallout: a source of microplastics in the environment? Mar Pollut Bull 104:290-293
30. Duis K, Coors A (2016) Microplastics in the aquatic and terrestrial environment: sources (with a specific focus on personal care products), fate and effects. Environ Sci Eur 28(1):2

31. Eich A, Mildenberger T, Laforsch C, Weber M (2015) Biofilm and diatom succession on polyethylene (PE) and biodegradable plastic bags in two marine habitats: early signs of degradation in the pelagic and benthic zone? PLOS ONE 10:e0137201

32. Elasri MO, Miller RV (1999) Study of the response of a biofilm bacterial community to UV radiation. Appl Environ Microbiol 65(5):2025-2031

33. El-Shahawi MS, Hamza A, Bashammakhb AS, Al-Saggaf WT (2010) An overview on the accumulation, distribution, transformations, toxicity and analytical methods for the monitoring of persistent organic pollutants. Talanta 80:1587-1597. https:// doi.org/10.1016/j.talanta.2009.09.055

34. Endo S, Koelmans AA (2016) Sorption of hydrophobic organic compounds to plastics in the marine environment: equilibrium. In: Takada H, Karapanagioti HK (eds) Hazardous chemicals associated with plastics in the marine environment, $\mathrm{Hdb}$ Env Chem. https://doi.org/10.1007/698_2016_11

35. Endo S, Takizawa R, Okuda K, Takada H, Chiba K, Kanehiro H, Ogi H, Yamashita R, Date T (2005) Concentration of polychlorinated biphenyls (PCBs) in beached resin pellets: variability among individual particles and regional differences. Mar Pollut Bull 50:1103-1114

36. Enyoh CE (2019) Microplastic pollution in Nigeria: a call for concern. 26th meeting of the Imo State chapter of the Chemical Society of Nigeria (CSN) held at Imo State University, Nigeria. https://doi.org/10.13140/RG.2.2.21027.9190

37. Enyoh CE, Verla AW, Egejuru NJ (2018) pH variations and chemometric assessment of borehole water in Orji, Owerri Imo State,Nigeria. J Environ Anal Chem. 5(2):1-9. https://doi. org/10.4172/2380-2391.1000238

38. Enyoh CE, Verla AW (2019) We are breathing plastic; don't just look down, look up. Presented at the 3rd IMSU world environment day international conference. https://doi.org/10.13140 /RG.2.2.21027.91680

39. Enyoh CE, Verla AW, Verla EN (2019) Uptake of microplastics by plant: a reason to worry or to be happy? World Sci News 131:256-267

40. Enyoh CE, Verla AW, Verla EN, Ibe FC, Amaobi CE (2019b) Airborne Microplastics: a review study on method for analysis, occurrence, movement and risks. Preprints, 2019080316 https://doi.org/10.20944/preprints201908.0316.v1

41. Erik S (2018) The missing science: Could our addiction to plastic be poisoning us? https://www.unenvironment.org/newsand-stories/story/missing-science-could-our-addiction-plast ic-be-poisoning-us. Accessed 28 Apr 2019

42. FAO (2016). The state of the worlds fisheries and aquaculture. Food and Agriculture Organization, pp 4-10

43. Fischer AC, Kroon JJ, Verburg TG, Teunissen T, Wolterbeek HT (2007) On the relevance of iron adsorption of container materials in small-volume experiments on iron marine chemistry: fe-55-aided assessment on capacity, affinity and kinetics. Mar Chem 107:533-546

44. Fisner M, Taniguchi S, Moreira F, Bícego MC, Turra A (2013) Polycyclic aromatic hydrocarbons (PAHs) in plastic pellets: variability in the concentration and composition at different sediment depths in a sandy beach. Mar Pollut Bull 70(12):219-226. https://doi.org/10.1016/j.marpolbul.2013.03.008

45. Foekema EM, De Gruijter C, Mergia MT, van Franeker JA, Murk AJ, Koelmans AA (2013) Plastic in North Sea fish. Environ Sci Technol 47:8818-8824

46. Foulon V, Le Roux F, Lambert C et al (2016) Colonization of polystyrene microparticles by Vibrio crassostreae: light and 
electron microscopic investigation. Environ Sci Technol 50:10988. https://doi.org/10.1021/acs.est.6b02720

47. Fotopoulou KN, Karapanagioti HK (2012) Surface properties of beached plastic pellets. Mar Environ Res 81:70-77

48. Frias JPGL, Sobral P, Ferreira AM (2010) Organic pollutants in microplastics from two beaches of the Portuguese coast. Mar Pollut Bull 60:1988-1992

49. Fuller S, Gautam A (2016) A procedure for measuring microplastics using pressurized fluid extraction. Environ Sci Technol 50:5774-5780

50. Gabriel FL, Routledge EJ, Heidelberger A, Rentsch D, Guenther K, Giger W et al (2008) Isomer-specific degradation and endocrine disrupting activity of nonylphenols. Environ Sci Technol. 42(17):6399-6408. https://doi.org/10.1021/es800577a

51. Gall SC, Thompson RC (2015) The impact of debris on marine life. Mar Pollut Bull 92(1-2):170-179. https://doi.org/10.1016/j. marpolbul.2014.12.041

52. Gambaro A, Manodori L, Zangrando R, Cincinelli A, Capodaglio G, Cescon P (2005) Atmospheric PCB concentrations at Terra Nova Bay, Antarctica. Environ Sci Technol 39:9406-9411. https ://doi.org/10.1021/es0510921

53. Gao F, Li J, Sun C, Zhang L, Jiang F, Cao W, Zheng L (2019) Study on the capability and characteristics of heavy metals enriched on microplastics in marine environment. Mar Pollut Bull 144:61-67. https://doi.org/10.1016/j.marpolbul.2019.04.039

54. Gasperi J, Wright SL, Dris R, France C, Corinne M, Mohamed G, Valérie L, Frank JK, Bruno T (2018) Microplastics in air: are we breathing it in? Curr Opin Environ Sci Health 1:1-5

55. GESAMP (2016) Sources, fate and effects of microplastics in the marine environment: part two of a global assessment. IMO/ FAO/UNESCO-IOC/UNIDO/WMO/IAEA/UN/UNEP/UNDP Joint group of experts on the scientific aspects of marine environmental protection, $220 \mathrm{p}$

56. GESAMP (2015) Sources, fate and effects of microplastics in the marine environment: a global assessment. https://doi. org/10.13140/RG.2.1.3803.7925

57. Goss KU, Schwarzenbach RP (2003) Rules of thumb for assessing equilibrium partitioning of organic compounds: successes and pitfalls. J Chem Educ 80(4):450-455

58. Gregory MR (1978) Accumulation and distribution of virgin plastic granules on New Zealand beaches. N Z J Mar Freshw Res 12:399-414

59. Greim H, Borm P, Schins R, Donaldson K, Driscoll K, Hartwig A, Kuempel E, Oberdorster G, Speit G (2001) Toxicity of fibers and particles report of the workshop held in Munich, Germany. Inhal Toxicol 13:737-754

60. Guo X, Wang J (2019) The phenomenological mass transfer kinetics model for $\mathrm{Sr}^{2+}$ sorption onto spheroids primary microplastics. Environ Pollut 250:737-745. https://doi.org/10.1016/j. envpol.2019.04.091

61. Hahladakisa JN, Costas AV, Roland W, Eleni I, Phil P (2018) An overview of chemical additives present in plastics: migration, release, fate and environmental impact during their use, disposal and recycling. J Hazard Mater 344:179-199

62. Hall NM, Berry KL, Rintoul EL, Hoogenboom MO (2015) Microplastic ingestion by scleractinian corals. Mar Biol 162:725-732

63. Harrison JP, Timothy JH, Melanie S, Alexander ST, Yon J, Jesus JO (2018) Microplastic-associated biofilms: a comparison of freshwater and marine environments. In: Wagner M, Lambert S (eds) Freshwater microplastics, Hdb Env Chem 58. https://doi. org/10.1007/978-3-319-61615-5_9

64. Heskett M, Takada H, Yamashita R, Yuyama M, Ito M, Geok YB, Ogata Y, Kwan C, Heckhausen A, Taylor H, Powell T, Morishige C, Young D, Patterson H, Robertson B, Bailey E, Mermoz J (2012) Measurement of persistent organic pollutants (POPs) in plastic resin pellets from remote islands: toward establishment of background concentrations for International Pellet Watch. Mar Pollut Bull 64:445-448

65. Hirai H, Takada H, Ogata Y, Yamashita R, Mizukawa K, Saha M, Kwan C, Moore C, Gray H, Laursen D, Zettler ER, Farrington JW, Reddy CM, Peacock EE, Ward MW (2011) Organic micropollutants in marine plastics debris from the open ocean and remote and urban beaches. Mar Pollut Bull 62:1683-1692

66. Hodson ME, Calum ADH, Andy C, Miranda TPM, Karen LT (2012) Plastic bag derived-microplastics as a vector for metal exposure in terrestrial invertebrates. Supporting information

67. Holmes LA, Turner A, Thompson RC (2012) Adsorption of trace metals to plastic resin pellets in the marine environment. Environ Pollut 160(1):42-48

68. Holmes LA, Turner A, Thompson RC (2014) Interactions between trace metals and plastic production pellets under estuarine conditions. Mar Chem 167:25-32

69. Hu JQ, Yang SZ, Guo L, Xu X, Yao T, Xie F (2017) Microscopic investigation on the adsorption of lubrication oil on microplastics. J Mol Liq 227:351-355

70. Huerta Lwanga E, Gertsen $\mathrm{H}$, Gooren $\mathrm{H}$, Peters $\mathrm{P}$, Salánki T, van der Ploeg M, Besseling E, Koelmans AA, Geissen V (2016) Microplastics in the terrestrial ecosystem: implications for Lumbricus terrestris (Oligochaeta, Lumbricidae). Environ Sci Technol 50:2685-2691

71. Hüffer T, Hofmann T (2016) Sorption of non-polar organic compounds by micro-sized plastic particles in aqueous solution. Environ Pollut 214:194-201

72. Hüffer T, Weniger AK, Hofmann T (2018) Sorption of organic compounds by aged polystyrene microplastic particles. Environ Pollut 236:218-225

73. Ibe FC, Isiukwu BO, Enyoh CE (2017) Trace metals analysis of soil and edible plant leaves from abandoned municipal waste dumpsite in Owerri, Imo state, Nigeria. World News Nat Sci (WNOFNS) 13:27-42

74. Inger LN, Claudia H, lan A, Kevin V T (2014) Microplastics in marine environments: occurrence, distribution and effects. Norwegian Institute for Water Research, report no. 6754-2014, project no. 14338, pp 1-71

75. Isiuku BO, Enyoh CE (2019) Phytoremediation of polluted waterbodies with aquatic plants: recent progress on heavy metal and organic pollutants. Preprints. https://doi.org/10.20944/prepr ints201909.0020.v1

76. Jean-Noël B (1980) An essay concerning mankind's evolution. Popul Sel Pap 4:1-13

77. Johansen MP, Cresswell T, Davis J, Howard DL, Howell N, Prentice $E$ (2019) Biofilm-enhanced adsorption of strong and weak cations onto different microplastic sample types: Use of spectroscopy, microscopy and radiotracer methods. Water Res. https://doi.org/10.1016/j.watres.2019.04.029

78. Ju H, Zhu D, Qiao M (2019) Effects of polyethylene microplastics on the gut microbial community, reproduction and avoidance behaviors of the soil springtail, Folsomia candida. Environ Pollut 247:890-897

79. Karami A, Golieskardi A, Ho YB, Larat V, Salamatinia B (2017) Microplastics in eviscerated flesh and excised organs of dried fish. Sci Rep 7(1):5473

80. Karami A, Abolfazl G, Cheng KC, Vincent L, Tamara SG, Babak S (2017) The presence of microplastics in commercial salts from different countries. Sci Rep 7:46173. https://doi.org/10.1038/ srep46173

81. Karapanagioti HK, Endo S, Ogata Y, Takada H (2011) Diffuse pollution by persistent organic pollutants as measured in plastic pellets sampled from various beaches in Greece. Mar Pollut Bull 62:312-317

82. Karapanagioti HK, Klontza I (2007) Investigating the properties of plastic resin pellets found in the coastal areas of Lesvos island. Global Nest J 9:71-76 
83. Karapanagioti HK, Klontza I (2008) Testing phenanthrene distribution properties of virgin plastic pellets and plastic eroded pellets found on Lesvos island beaches (Greece). Mar Environ Res 65:283-290

84. Karapanagioti HK, Siavalas G, Kalaitzidis S, Papatheodorou G, Christanis K (2009) Distribution of polycyclic aromatic hydrocarbons (PAHs) in the Gulf of Aliveri, Central Greece. In: Proceedings of the 9th National Greek Symposium on Oceanography and Fishery, Patras, vol 1. pp 251-255

85. Karapanagioti HK, Ogata Y, Takada H (2010) Eroded plastic pellets as monitoring tools for polycyclic aromatic hydrocarbons (PAH): laboratory and field studies. Global Nest J. 12:327-334

86. Kaya AT, Meral Y, Senem CB (2018) Ubiquitous exposure to microfiber pollution in the air. Eur Phys J Plus 133(488):1-10. https://doi.org/10.1140/epjp/i2018-12372-7

87. Kim HM, Lee D-K, Long NP, Kwon SW, Park JH (2019) Uptake of nanopolystyrene particles induces distinct metabolic profiles and toxic effects in Caenorhabditis elegans. Environ Pollut 246:578-586

88. Kirstein IV, Kirmizi S, Wichels A, Garin-Fernandez A, Erler R, Löder M, Gerdts G (2016) Dangerous hitchhikers? Evidence for potentially pathogenic Vibrio spp. on microplastic particles. Mar Environ Res 120:1-8

89. Kokalj AJ, Horvat P, Skalar T, Kržan A (2018) Plastic bag and facial cleanser derived microplastic do not affect feeding behavior and energy reserves of terrestrial isopods. Sci Total Environ 615:761-766

90. Lau C, Anitole K, Hodes C, Lai D, Pfahles-Hutchens A, Seed J (2007) Perfluoroalkyl acids: a review of monitoring and toxicological findings. Toxicol. Sci. 99:366-394

91. Lee H, Shim WJ, Kwon JH (2014) Sorption capacity of plastic debris for hydrophobic organic chemicals. Sci Total Environ 470-471:1545-1552

92. Lei L, Liu M, Song Y, Lu S, Hu J, Cao C, Xie B, Shi H, He D (2018) Polystyrene (nano) microplastics cause size-dependent neurotoxicity, oxidative damage and other adverse effects in Caenorhabditis elegans. Environ Sci 5:2009-2020

93. Lester EB, John SA, Richard DO (1966) Effect of electrostatic charge on the contamination of plastic food containers by airborne bacterial spores. Appl Microbiol 14(6):905-913

94. Li J, Zhang K, Zhang H (2018) Adsorption of antibiotics on microplastics. Environ Pollut 237:460-467

95. Li L, Zhou Q, Yin N, Tu C, Luo Y (2019) Uptake and accumulation of microplastics in an edible plant. Chin Sci Bull 64:928-934

96. Lin SB, Hwang KS, Tsay SY, Cooper SL (1985) Segmental orientation studies of polyether polyurethane block copolymers with different hard segment lengths and distributions. Colloid Polym Sci 263:128-140

97. Linares $V$, Bellés $M$, Domingo JL (2015) Human exposure to PBDE and critical evaluation of health hazards. Arch Toxicol 89:335-356

98. Liu H, Yang X, Liu G, Liang C, Xue S, Chen H, Ritsema CJ, Geissen $V$ (2017) Response of soil dissolved organic matter to microplastic addition in Chinese loess soil. Chemosphere 185:907-917

99. Liu M, Lu S, Song Y, Lei L, Hu J, Lv W, Zhou W, Cao C, Shi H, Yang $X$ (2018) Microplastic and mesoplastic pollution in farmland soils in suburbs of Shanghai, China. Environ Pollut 242:855-862

100. Liu K, Xiaohui W, Tao F, Pei X, Lixin Z, Daoji L (2019) Source and potential risk assessment of suspended atmospheric microplastics in Shanghai. Sci Total Environ 675:462-471

101. Llorca M, Farré M, Karapanagioti HK, Barceló D (2014) Levels and fate of perfluoroalkyl substances in beached plastic pellets and sediments collected from Greece. Mar Pollut Bull 87:286-291
102. Llorca M, Farré $M$, Tavano MS, Alonso B, Koremblit G, Barceló D (2012) Fate of a broad spectrum of perfluorinated compounds in soils and biota from Tierra del Fuego and Antarctica. Environ Pollut 163:158

103. Llorca M, Gabriella S, Monica M, Damia B, Marinella F (2018) Adsorption of perfluoroalkyl substances on microplastics under environmental conditions. Environ Pollut 235:680-691

104. Lobelle D, Cunliffe M (2011) Early microbial biofilm formation on marine plastic debris. Mar Pollut Bull 62(1):197-200

105. Loeb G I, Neihof R A (1975) Marine conditioning films. In: Applied chemistry at protein interfaces, vol 145 . American Chemical Society, Washington, DC, pp 319-335

106. Lu Z, Gan J (2014) Isomer-Specific biodegradation of nonylphenol in river sediments and structure-biodegradability relationship. Environ Sci Technol 48(2):1008-1014. https://doi. org/10.1021/es403950y

107. Lusher A, Hollman P, Mendoza-Hill J (2017) Microplastics in fisheries and aquaculture: status of knowledge on their occurrence and implications for aquatic organisms and food safety. FAO fisheries and aquaculture technical paper, 615

108. Lv W, Zhou W, Lu S, Huang W, Yuan Q, Tian M, Lv W, He D (2019) Microplastic pollution in rice-fish co-culture system: a report of three farmland stations in Shanghai, China. Sci Total Environ 652:1209-1218

109. Masó M, Fortuño JM, de Juan S, Demestre M (2016) Microfouling communities from pelagic and benthic marine plastic debris sampled across Mediterranean coastal waters. Sci Mar 80:117-127

110. Massos A, Turner A (2017) Cadmium, lead and bromine in beached microplastics. Environ Pollut. https://doi. org/10.1016/j.envpol.2017.04.0

111. Mato $\mathrm{Y}$, Isobe $T$, Takada $\mathrm{H}$, Kanehiro $\mathrm{H}$, Ohtake $\mathrm{C}$, Kaminuma $\mathrm{T}$ (2001) Plastic resin pellets as a transport medium for toxic chemicals in the marine environment. Environ Sci Technol 35:318-324

112. Mincer TJ, Zettler ER, Amaral-Zettler LA (2016) Biofilms on plastic debris and their influence on marine nutrient cycling, productivity, and hazardous chemical mobility. Springer, Berlin

113. Mizukawa K, Takada H, Ito M, Geok YB, Hosoda J, Yamashita $R$, Ferreira AM (2013) Monitoring of a wide range of organic micropollutants on the Portuguese coast using plastic resin pellets. Mar Pollut Bull 70(1-2):296-302

114. Mohsen M, Wang Q, Zhang L, Sun L, Lin C, Yang H (2019) Heavy metals in sediment, microplastic and sea cucumber Apostichopus japonicus from farms in China. Mar Pollut Bull 143:42-49. https://doi.org/10.1016/j.marpolbul.2019.04.025

115. Morais S, Costa FG, Pereira ML (2012) Heavy metals and human health. In: Oosthuizen J (ed) Environmental health - emerging issues and practice, vol 2012. pp 227-246

116. Muhamed AP, Saly T (2011) Bioaccumulation of trace metals in biofilms formed on aluminium and steel in aquatic environment. Fish Technol 48(1):1-21

117. Munier B, Bendell LI (2018) Macro and micro plastics sorb and desorb metals and act as a point source of trace metals to coastal ecosystems. PLoS ONE 13(2):e0191759. https://doi. org/10.1371/journal.pone.0191759

118. Murray F, Cowie PR (2011) Plastic contamination in the decapod crustacean Nephrops norvegicus (Linnaeus, 1758). Mar Pollut Bull 62:1207-1217

119. Ocampo-Perez R, Aguilar-Madera CG, Díaz-Blancas V (2017) $3 \mathrm{D}$ modeling of overall adsorption rate of acetaminophen on activated carbon pellets. Chem Eng J 321:510-520

120. Ocampo-Perez R, Leyva-Ramos R, Alonso-Davila P, Rivera-Utrilla $\mathrm{J}$, SanchezPolo M (2010) Modeling adsorption rate of pyridine onto granular activated carbon. Chem Eng J 165:133-141 
121. Ogata $Y$, Takada H, Mizukawa K, Iwasa S, Endo S, Mato Y, Saha M, Booyatumanondo R, Zakaria MP, Dung LQ, Gordon M, Moore C, Karapanagioti HK, Thompson R (2009) International Pellet Watch: global monitoring of persistent organic pollutants (POPs) in coastal waters. 1. Initial phase data on PCBs, DDTs, and HCHs. Mar Pollut Bull 58:1437-1446

122. Ojeda JJ, Romero-González ME, Banwart SA (2009) Analysis of bacteria on steel surfaces using reflectance micro-Fourier transform infrared spectroscopy. Anal Chem 81(15):6467-6473. https://doi.org/10.1021/ac900841c

123. Okoh Al (2006) Biodegradation alternative in the cleanup of petroleum hydrocarbon pollutants. Biotechnol Mol Biol Rev 1(2):38-50

124. Pascal MA, Zabik ME, Zabik MJ, Hernandez RJ (2005) Uptake of polychlorinated biphenyls (PCBs) from an aqueous medium by polyethylene, polyvinyl chloride, and polystyrene films. J Agric Food Chem 53:164-169

125. Paula ST, Vladimír K, Susana L, Cornelis AMV (2019) Partitioning of chemical contaminants to microplastics: sorption mechanisms, environmental distribution and effects on toxicity and bioaccumulation. Environ Pollut 252:1246-1256. https://doi.org/10.1016/j.envpol.2019.06.030

126. Peden-Adams M, Keller J, Eudaly J, Berger J, Gilkeson G, Keil D (2008) Suppression of humoral immunity in mice following exposure to perfluorooctane sulfonate. Toxicol Sci 104:144-154

127. Pignatello JJ, Xing B (1996) Mechanisms of slow sorption of organic chemicals to natural particles. Environ Sci Technol 30(1):1-11

128. Pimentel JC, Avila R, Lourenço AG (1975) Respiratory disease caused by synthetic fibres: a new occupational disease. Thorax 30:204-219

129. Qi Y, Yang X, Pelaez AM, Lwanga EH, Beriot N, Gertsen H, Garbeva P, Geissen V (2018) Macro-and micro-plastics in soil-plant system: effects of plastic mulch film residues on wheat (Triticum aestivum) growth. Sci Total Environ 645:1048-1056

130. Raymont JEG (1980) Chapter 6: Factors limiting primary production: light and temperature. Plankton and productivity in the oceans, 2nd edn. Pergamon, Amsterdam, pp 259-296

131. Raymont JEG (1980) Chapter 7: Factors limiting primary production: nutrients. Plankton and Productivity in the Oceans, 2nd edn. Pergamon, Amsterdam, pp 297-345

132. Reisser J, Shaw J, Hallegraeff G, Proietti M, Barnes DK, Thums M, Wilcox C, Hardesty BD, Pattiaratchi C (2014) Millimetersized marine plastics: a new pelagic habitat for microorganisms and invertebrates. PLoS ONE 9:e100289

133. Richard H (2016) Biofilm facilitates metal accumulation onto new plastic pellets in aquatic environments. A thesis submitted to the faculty of San Francisco State University. Assessed 30 Apr 2019

134. Rios LM, Moore C, Jones PR (2007) Persistent organic pollutants carried by synthetic polymers in the ocean environment. Mar Pollut Bull 54:1230-1237

135. Ritter L, Solomon KR, Forget J, Stemeroff M, O'Leary C (2007) Persistent organic pollutants. United Nations Environment Programme

136. Rocha-Santos T, Duarte AC (2015) A critical overview of the analytical approaches to the occurrence, the fate and the behavior of microplastics in the environment. Trends Anal Chem 65:47-53

137. Rochman C, Hentschel BT, Teh SJ (2014) Long-term sorption of metals is similar among plastic types: implications for plastic debris in aquatic environments. https://doi.org/10.1371/journ al.pone.0085433

138. Roh Y, Gao H, Vali H et al (2006) Metal reduction and iron biomineralization by a psychrotolerant Fe(III)-reducing bacterium,
Shewanella sp. strain PV-4. Appl Environ Microbiol 72(5):32363244. https://doi.org/10.1128/AEM.72.5.3236-3244.2006

139. Rusconi R, Garren M, Stocker R (2014) Microfluidics expanding the frontiers of microbial ecology. Annu Rev Biophys 43:65-91. https://doi.org/10.1146/annurev-biophys-051013-022916

140. Rutherford ST, Bassler BL (2012) Bacterial quorum sensing: its role in virulence and possibilities for its control. Cold Spring Harb Perspect 2:a012427

141. Ryan PG, Bouwman H, Moloney CL, Yuyama M, Takada H (2012) Long-term decreases in persistent organic pollutants in South African coastal waters detected from beached polyethylene pellets. Mar Pollut Bull 64:2756-2760

142. Saha M, Togo A, Mizukawa K, Murakami M, Takada H, Zakaria $\mathrm{MP}$, Chiem NH, Tuyen BC, Prudente M, Boonyatumanond $\mathrm{R}$ (2009) Sources of sedimentary PAHs in tropical Asian waters: differentiation between pyrogenic and petrogenic sources by akyl homolog abundance. Mar Pollut Bull 58:189-200. https://doi.org/10.1016/j.marpolbul.2008.04.049

143. Savoca MS, Wohlfeil ME, Ebeler SE, Nevitt GA (2016) Marine plastic debris emits a keystone infochemical for olfactory foraging seabirds. Sci Adv 2(11):el 600395

144. Schauder S, Bassler BL (2001) The languages of bacteria. Genes Dev 15:1468-1480

145. Scheurer M, Bigalke M (2018) Microplastics in Swiss floodplain soils. Environ Sci Technol 52:3591-3598

146. Skinner SM, Gaynor J, Sohl GW (1956) Electrostatic charges in plastics. Mod Plast 33:127-136

147. Smith M, David CL, Chelsea MR, Roni AN (2018) Microplastics in seafood and the implications for human health. Curr Environ Health Rep 5:375-386

148. Soares A, Guieysse B, Jefferson B, Cartmell E, Lester JN (2008) Review article: nonylphenol in the environment: a critical review on occurrence, fate, toxicity and treatment in wastewaters. Environ Int 34(7):1033-1049. https://doi. org/10.1016/j.envint.2008.01.004

149. Solano C, Echeverz M, Lasa I (2014) Biofilm dispersion and quorum sensing. Curr Opin Microbiol 18:96-104

150. Solly SRB, Shanks V (1976) Organochlorine residues in New Zealand birds and mammals. 2. Polychlorinated biphenyls. $\mathrm{N}$ Z J Sci 19:53-55

151. Souza PR, Dotto GL, Salau NPG (2017) Detailed numerical solution of pore volume and surface diffusion model in adsorption systems. Chem Eng Res Des 122:298-307

152. Srey S, Jahid IK, Ha SD (2013) Biofilm formation in food industries: a food safety concern. Food Control 31:572-585

153. Staniszewska M, Graca B, Nehring I (2016) The fate of bisphenol A, 4-tert-octylphenol and 4-nonylphenol leached from plastic debris into marine water-experimental studies on biodegradation and sorption on suspended particulate matter and nano- $\mathrm{TiO}_{2}$. Chemosphere 145:535-542. https:// doi.org/10.1016/j.chemosphere.2015.11.081

154. Statista (2018) Global plastic production statistics. https:// www.statista.com/statistics/282732/global-production-ofplastics-since-1950/. Accessed 3 Apr 2019

155. Sun $M$, Ye $M$, Jiao W, Feng $Y, Y u$, Liu $M$, Jiao J, He X, Liu $K$, Zhao $Y$ (2018) Changes in tetracycline partitioning and bacteria/phagecomediated ARGs in microplastic-contaminated greenhouse soil facilitated by sophorolipid. J Hazard Mater 345:131-139

156. Sven S, Christiane Z, Olaf AC, Peter G (2019) Microplastic-contaminant interactions: influence of nonlinearity and coupled mass transfer. Environ Toxicol Chem. https://doi.org/10.1002/ etc. 4447

157. Tcaciuc AP, Apell JN, Gschwend PM (2015) Modeling the transport of organic chemicals between polyethylene 
passive samplers and water in finite and infinite bath conditions. Environ Toxicol Chem 34(12):2739-2749

158. Teuten EL, Jovita MS, Detlef RUK, Morton AB, Susanne J, Annika B, Steven JR, Richard CT, Tamara SG, Rei Y, Daisuke O, Yutaka W, Charles M, Pham HV, Touch ST, Maricar P, Ruchaya B, Mohamad PZ, Kongsap A, Yuko O, Hisashi H, Satoru I, Kaoruko M, Yuki H, Ayako I, Mahua S, Hideshige T (2009) Transport and release of chemicals from plastics to the environment and to wildlife. Philos Trans R Soc Lond B Biol Sci 364:2027-2045

159. Teuten EL, Rowland SJ, Galloway TS, Thompson RC (2007) Potential for plastics to transport hydrophobic contaminants. Environ Sci Technol 41:7759-7764

160. Thiele B, Guenther K, Schwuger MJ (1997) Alkylphenol ethoxylates: trace analysis and environmental behaviour. Chem Rev 97(8):3247-3272. https://doi.org/10.1021/cr970323m

161. Tsuchiya $Y$, Ikenaga M, Kumiawan A, Hiraki A, Arakawa T, Kusakabe R, Morisaki H (2009) Nutrient-rich microhabitats within biofilms are synchronized with the external environment. Microbes Environ 24(1):43-51

162. Ugolini A, Ungherese G, Ciofini M, Lapucci A, Camaiti M (2013) Microplastic debris in sandhoppers. Estuar Coast Shelf Sci 129:19-22

163. UNEP (2016) Marine debris: understanding, preventing and mitigating the significant adverse impacts on marine and coastal. Secretariat of the Convention on Biological Diversity. Biodiversity. Technical series no. 83

164. Uwah El, Ndahi NP, Abdulrahman Fl, Ogugbuaja VO (2011) Heavy metal levels in spinach (Amaranthus caudatus) and lettuce (Lactuca sativa) grown in Maiduguri, Nigeria. J Environ Chem Ecotoxicol 3(10):264-271

165. Van A, Rochman CM, Flores EM, Hill KL, Vargas E, Vargas SA, Hoh E (2012) Persistent organic pollutants in plastic marine debris found on beaches in San Diego, California. Chemosphere 86:258-263

166. Van Cauwenberghe L, Janssen CR (2014) Microplastics in bivalves cultured for human consumption. Environ Pollut 2014(193):65-70

167. van Hullebusch ED, Zandvoort MH, Lens PNL (2003) Metal immobilisation by biofilms: mechanisms and analytical tools. Rev Environ Sci Bio/Technol 2(1):9-33

168. Vanhaecke L, Van Hoof N, Van Brabandt W, Soenen B, Heyerick A, De Kimpe N, De Keukeleire D, Verstraete W, Van de Wiele T (2006) Metabolism of the food-associated carcinogen 2-amino1- methyl-6-phenylimidazo[4,5 b]pyridine by human intestinal microbiota. J Agric Food Chem 54(9):3454-3461

169. Verla AW, Verla EN, Chigbo MA, Kelechi CL, Ngozi OS, Enyoh CE (2019) Biomonitoring of heavy metals in blood and urine of African children from Owerri metropolis, Eastern Nigeria. J Chem H Risks 9(1):11-26

170. Verla AW, Verla EN, Enyoh CE, Leizou K, Peter NO (2019b) Using physicochemical properties in assessment of river water for consumption and irrigation in Nigeria. Eurasian J Anal Chem (accepted manuscript)

171. Verla AW, Verla EN, Nwaugo VO, Leizou KE (2017) How metal concentrations could affect enzyme activities: a case study of a range, near Port Harcourt, Rivers State,Nigeria. Res J Recent Sci 6(7):40-52

172. Verla AW, Enyoh CE, Verla EN (2019) Microplastics, an emerging concern: a review of analytical techniques for detecting and quantifying microplatics. Anal Methods Environ Chem J 12:15-32. https://doi.org/10.24200/amecj

173. Violante A, Pigna M (2008) Sorption-desorption processes of metals and metalloids in soil environments. In: 5th international symposium ISMOM 2008-November 24th-28th, 2008_Pucón, Chile. Accessed 30 Apr 2019
174. Vom Saal FS, Myers JP (2008) Bisphenol A and risk of metabolic disorders. J Am Med Assoc 300:1353-1355

175. Wang J, Jinping P, Zhi T, Yifan G, Zhiwei Z, Qiuqiang C, Liqi C (2017) Microplastics in the surface sediments from the Beijiang River littoral zone: composition, abundance, surface textures and interaction with heavy metals. Chemosphere 171:248-258

176. Wang WF, Wang J (2018) Different partition of polycyclic aromatic hydrocarbon on environmental particulates in freshwater: microplastics in comparison to natural sediment. Ecotoxicol Environ Saf 147:648-655

177. Wang WF, Wang J (2018) Comparative evaluation of sorpion kinetics and isotherm of pyrene onto microplsatics. Chemosphere 193:567-573

178. Warheit DB, Hart GA, Hesterberg TW, Collins JJ, Dyer WM, Swaen GMH, Castranova V, Soiefer Al, Kennedy GL (2001) Potential pulmonary effects of man-made organic fiber (MMOF) dusts. Crit Rev Toxicol 31:697-736

179. Webster L, Twigg M, Megginson C, Walsham P, Packer G, Moffat C (2003) Aliphatic hydrocarbons and polycyclic aromatic hydrocarbons (PAHs) in sediments collected from the 110 mile hole and along a transect from $58.320 \mathrm{~N} 110.380 \mathrm{~W}$ to the inner Moray Firth, Scotland. J Environ Monit 5:395-403

180. WHO (1997) Determination of airborne fibre number concentrations: a recommended method, by phasecontrast optical microscopy (membrane filter method). 1997 [no volume]

181. Woodland PC, Ziegler EE (1951) Static dust collection of plastics. Mod Plast 28:95-106

182. Worldometers (2019) World population clock: 7.7 billion people. Worldometers. www.worldometers.info. Accessed $28 \mathrm{Apr}$ 2019

183. Wright SL, Kelly FJ (2017) Plastic and human health: a micro issue? Environ Sci Technol 51(12):6634-6647

184. Wright SL, Thompson RC, Galloway TS (2013) The physical impacts of microplastics on marine organisms: a review. Environ Pollut 178:483-492

185. Wu B, Taylor CM, Knappe DRU, Nanny MA, Barlaz MA (2001) Factors controlling alkylbenzene sorption to municipal solid waste. Environ Sci Technol 35:4569-4576

186. Wu CX, Zhang K, Huang X, Liu J (2016) Sorption of pharmaceuticals and personal care products to polyethylene debris. Environ Sci Pollut Res 23:8819-8826

187. Wyszkowska J, Kucharski J (2003) Effect of soil contamination with copper on its enzymatic activity and physicochemical properties. Electron J Agric Univ 6(2):389-395

188. Wyszkowska J, Wyszkowski M (2003) Effect of cadmium and magnesium on enzymatic activity in soil. Pol J Environ Stud 12(4):473-479

189. Xiong ZT (1998) Lead uptake and effects on seed germination and plant growth in a lead hyperaccumalator Brassica pekinensis. Rupr Bull Environ Contam Toxicol 60:285-291

190. Xu B, Liu F, Brookes PC, Xu J (2018) The sorption kinetics and isotherms of sulfamethoxazole with polyethylene microplastics. Mar Pollut Bull 131:191-196

191. Yang D, Shi H, Li L, Li J, Jabeen K, Kolandhasamy P (2015) Microplastic pollution in table salts from China. Environ Sci Technol 49(22):13622-13627

192. Yao F, Weiyun JK (2010) Drug release kinetics and transport mechanisms of non-degradable and degradable polymeric delivery systems. Expert Opin Drug Delivery 7(4):429-444

193. Yeo BG, Takada H, Hosoda J, Kondo A, Yamashita R, Saha M, Maes T (2017) Polycyclic aromatic hydrocarbons (PAHs) and hopanes in plastic resin pellets as markers of oil pollution via international pellet watch monitoring. Arch Environ Contam Toxicol 73(2):196-206. https://doi.org/10.1007/s0024 4-017-0423-8 
194. Zakaria MP, Horinouchi A, Tsutsumi S, Takada H, Tanabe S, Ismail A (2000) Oil pollution in the straits of Malacca, Malaysia: application of molecular markers for source identification. Environ Sci Technol 34(7):1189-1196

195. Zakaria MP, Takada H (2007) 16-Case study: oil spills in the strait of Malacca, Malaysia. In: Stout ZWA (ed) Oil spill environmental forensics. Academic Press, Burlington, pp 489-504. https://doi.org/10.1016/b978-012369523-9.50020-3

196. Zettler ER, Mincer TJ, Amaral-Zettler LA (2013) Life in the "Plastisphere": microbial communities on plastic marine debris. Environ Sci Technol 47(13):7137-7146

197. Zhang GS, Liu YF (2018) The distribution of microplastics in soil aggregate fractions in southwestern China. Sci Total Environ 642:12-20

198. Zhang S, Yang X, Gertsen H, Peters P, Salánki T, Geissen V (2018) A simple method for the extraction and identification of light density microplastics from soil. Sci Total Environ 616:1056-1065

199. Zhang H, Jiaqing W, Zhou B, Zhou Y, Dai Z, Zhou Q, Chriestie P, Lu Y (2018) Enhanced adsorption of oxytetracycline to weathered microplastic polystyrene: kinetics, isotherms and influencing factors. Environ Pollut 243:1550-1557

200. Zhou Q, Tian C, Luo Y (2017) Various forms and deposition fluxes of microplastics identified in the coastal urban atmosphere. Chin Sci Bull 62(33):3902-3910. https://doi.org/10.1360/ N972017-00956

201. Zhu BK, Fang YM, Zhu D, Christie P, Ke X, Zhu YG (2018) Exposure to nanoplastics disturbs the gut microbiome in the soil oligochaete Enchytraeus crypticus. Environ Pollut 239:408-415

202. Zhu D, Chen QL, An XL, Yang XR, Christie P, Ke X, Wu LH, Zhu YG (2018) Exposure of soil collembolans to microplastics perturbs their gut microbiota and alters their isotopic composition. Soil Biol Biochem 116:302-310

203. Zhu F, Changyin Z, Chao W, Cheng G (2019) Occurrence and ecological impacts of microplastics in soil systems: a review. Bull Environ Contam Toxicol. https://doi.org/10.1007/s0012 8-019-02623-z

Publisher's Note Springer Nature remains neutral with regard to jurisdictional claims in published maps and institutional affiliations. 